\begin{abstract}
Cross-border e-commerce is becoming increasingly popular around the world. With the development of technology, competition has gradually shifted from commodity-based attributes, such as cost and quality, to a supply chain's service capacity for e-commerce. Within this context, the present paper delineates how cross-border e-commerce firms can generate supply chain service capabilities that yield improvements in supply chain relationship quality to e-tailors and other platform users. Insights are derived through data collected via a multiple case study approach based on four Chinese cross-border e-commerce enterprises (OSell, Zongteng, BizArk and Linca); data were collected from 41 semi-structured interviews, field visits and secondary data. Relying on the service dominant logic as the theoretical foundation, we identify three supply chain resources (flows related to information, logistics and finance) and their interplay as being critical for the development of supply chain service capabilities, which in turn lead to an improvement in the quality of supply chain relationships (assessed by the dimensions of trust improvement/commitment, risk mitigation, and customer satisfaction). The results offer important insights into how to best manage relationships by cross-border ecommerce firms in order to foster relationship quality, an attribute that has become so critical today for competitive differentiation.
\end{abstract}

Keywords: Service supply chains, Cross-border e-commerce, Service dominant logic, Case studies 
Cross-border e-commerce firms as supply chain integrators:

the management of three flows

Ying Wang, PhD (first author)

School of Economics and Management, Minjiang University

Fuzhou, P.R. China

Email: wang@mju.edu.cn; Tel: +86 13055783377

Fu Jia, PhD (second and correspondence author)

The York Management School

University of York

Heslington, York YO10 5DD

Tel: +44 (0)1904 324855

Email: fu.jia@york.ac.uk

Tobias Schoenherr, PhD (Third author)

Department of Supply Chain Management, Broad College of Business

Michigan State University, North Business College Complex

632 Bogue St., Room N370, East Lansing MI, 48824, USA

Email: schoenherr@broad.msu.edu; Tel: +1 5174326437

Yu Gong, PhD (Fourth author)

Southampton Business School,

University of Southampton,

Southampton SO17 1BJ, UK

Tel: +44 (0) 7424231515

Email:y.gong@soton.ac.uk

Lujie Chen (Fifth and corresponding author)

Associate professor in Management

International Business School Suzhou

Xi'an Jiaotong-Liverpool University, Suzhou, China

Email: Lujie.Chen@xjtlu.edu.cn

Acknowledgement: This research was funded by National Social Science Foundation Project, grant number 15 CJY010. 


\title{
Cross-border e-commerce firms as supply chain integrators: \\ the management of three flows
}

\begin{abstract}
Cross-border e-commerce is becoming increasingly popular around the world. With the development of technology, competition has gradually shifted from commodity-based attributes, such as cost and quality, to a supply chain's service capacity for e-commerce. Within this context, the present paper delineates how cross-border e-commerce firms can generate supply chain service capabilities that yield improvements in supply chain relationship quality to e-tailors and other platform users. Insights are derived through data collected via a multiple case study approach based on four Chinese cross-border ecommerce enterprises (OSell, Zongteng, BizArk and Linca); data were collected from 41 semi-structured interviews, field visits and secondary data. Relying on the service dominant logic as the theoretical foundation, we identify three supply chain resources (flows related to information, logistics and finance) and their interplay as being critical for the development of supply chain service capabilities, which in turn lead to an improvement in the quality of supply chain relationships (assessed by the dimensions of trust improvement/commitment, risk mitigation, and customer satisfaction). The results offer important insights into how to best manage supply chain resources in relation to the three flows by cross-border e-commerce firms in order to foster relationship quality, an attribute that has become so critical today for competitive differentiation.
\end{abstract}

Keywords: Service supply chains, Cross-border e-commerce, Service dominant logic, Case studies

\section{Introduction}

With the accessibility and popularity of the Internet, as well as the advancement of information technology (IT), e-commerce has been gaining momentum in the global 
marketplace. While China was late in making inroads in this area, compared to developed countries, it has been catching up quickly (Johnson-Page and Thatcher, 2001). As such, over the last few years, China's cross-border e-commerce sales have increased at an exponential rate, thanks to an improved Internet infrastructure, mounting Internet users and a better e-commerce environment. According to the Chinese Ministry of Commerce (2018), the total amount of imports and exports of cross-border e-commerce commodities inspected and released by customs was 90.24 billion RMB in 2017, which reflected an increase of 80.6 percent year-over-year; the average annual rate of increase during the years 2010-2017 was approximately 20 percent.

As of 2016, according to Xinhuanet (2016), there are over 200,000 cross-border ecommerce enterprises and more than 5,000 e-commerce platforms in China. With the strong support of national policies, e-commerce firms are driving the development of cross-border supply chain activities. The consulting firm iResearch (2018) estimates that cross-border e-commerce will continue on the current trajectory in the coming years, taking over an increasingly larger share of total international trade. Similarly, Van Heel et al. (2011) predict that by 2025, annual global cross-border e-commerce revenues will be between 250 and 350 billion US dollars, with China and other Asia countries accounting for 40 percent of this total amount.

Despite the prosperity of cross-border e-commerce worldwide, there are still obstacles that constrain market growth, such as unreliable and lengthy transit times, complex and ambiguous return processes, bottlenecks at customs, limited transparency on delivery, price opacity, and limited ability to alter delivery times and locations (Van Heel et al., 2011). Specific obstacles in the Chinese context include data collection and processing difficulties, customs clearance, logistics challenges, as well as the efficiency associated with electronic payment refunding, a preferential policy issued by the Chinese government (Inama and Sim, 2015). According to China's Ministry of Commerce (2015), China's cross-border e-commerce development had been severely impeded by the 
unreasonable overall system complexity, inefficient customs clearance and imperfect infrastructure.

Since services, rather than products, have become the foundations of e-marketplace success and differentiation (Standing and Standing, 2015), many Chinese cross-border ecommerce enterprises are transitioning from a product-dominant logic to a servicedominant (S-D) logic (Xie et al., 2016; Ayala et al., 2019; Gang, 2019). While the former emphasizes the physical exchange of the product, with limited interaction between buyer and seller; the latter stresses the integration of product offerings with services, to enhance the value and experience of the customer. As such, enterprises are building on their existing business infrastructure to construct services supply chains, with the objective of providing better services accompanying the physical product before, during and after the sale.

The consideration of services in cross-border e-commerce is especially critical. As such, cross-border e-commerce is, in itself, a complex system, integrating multiple types of service offerings, such as cross-border trade services, electronic payment and logistics services, customs declaration and inspection services, and legal advice services (Baruca and Zolfagharian, 2012). E-commerce service supply chains constitute a network, which means that breakdowns in any particular link do not influence the operations of any single physical entity due to the inherent redundancy (Sanchez-Rodrigues et al., 2010). This is in contrast to the traditional service supply chain, which consists of a one-way flow of information starting with suppliers and ending with consumers; such a setup reduces flexibility and makes the system prone to any single part affecting the entire supply chain.

To meet the requirements of today's scrutinizing customers, cross-border ecommerce enterprises need to cooperate with both goods suppliers and service providers, such as logistics services companies and third-party payment platforms. The physical entities of the service supply chain include domestic customers, overseas businesses, cross-border e-commerce websites, and logistics enterprises, both at home and abroad (Hameri and Hintsa, 2009). Within this context, cross-border e-commerce 
platforms are the core of the supply chain, connecting businesses, customers, logistics enterprises and other service providers, offering supply chain management services in an integrated fashion.

Supply chain management (SCM) is the integration of upstream and downstream organizations, and the management of information, logistics and financial flows, with the objective to efficiently and effectively manage the whole (Mentzer et al., 2001; Christopher, 2016; Coyle et al., 2017). While the three inherent flows are considered as essential (Le and Ng, 1997; Singhal and Singhal, 2012), where insight is still missing is how to manage the three flows given the intrinsic relationships between them (Lambert et al., 1998; Rai et al., 2006; Lambert and Enz, 2017). The service supply chains of crossborder e-commerce companies present an intriguing context to examine this phenomenon, since they provide services to manufacturing firms and overseas customers using advanced technologies as a core competence.

Amazon provides a vivid example of how an e-commerce company adopts the S-D logic along the three flows. It has been disturbing the traditional retail market by launching online platforms with advanced IT architecture and strong data analysis capabilities to provide better customer services, for example in the form of enhanced product reviews and recommendations. It also moved into warehousing at the early stages in order to provide rapid delivery services to customers and storage/transportation services for its online platform sellers. In addition, it provides a one click process for customers to provide smooth financial transactions (Wells et al., 2018).

Nevertheless, how these services are provided within this context, and how the three flows interact and are combined to provide these services, is not clear to practitioners and academics. The S-D logic thus seems to be promising to utilize as a theoretical lens to explore cross-border e-commerce platforms (Lusch et al., 2006, 2007; Lusch, 2011; Vargo and Lusch, 2004; Vural et al., 2017). Specifically, within this context, we aim to answer the following research questions:

- What services do cross-border e-commerce firms provide, and how can they be mapped against the three-flow framework? 
- How can cross-border e-commerce firms improve supply chain relationship quality through the management of the three flows?

This paper proceeds as follows. The next section reviews the theoretical background of the S-D logic and research in services supply chain management, with a specific focus on the three flows in e-commerce SCM. We then outline our multiple case study research methodology, which is followed by the case description and the cross case analysis and its discussion. We conclude with highlighting our contributions, acknowledge limitations and offer future research directions.

\section{Literature review}

\subsection{S-D logic and service supply chain management}

The shift from a functional focus, where each department pursued its own objectives independent of other departments' objectives, to a more integrated focus on both internal and external relationships, aiming to deliver a consistent value proposition to the end customer, also taking a network perspective, has been taking place over the last two decades (Bovet and Martha, 2000; Gunasekaran and Ngai, 2004; Sampson and Spring, 2012; Lambert and Enz, 2017). This transition had been trigged by constant changes in consumption patterns and customer demands, necessitating firms to adapt their operational thinking based on a product-dominant logic to a service-dominant one. Research into services supply chain management thus represents a promising avenue (Giannakis, 2011), being reflected in the field of service sciences (Sampson and Spring, 2012).

Service supply chains can be complex value networks that contain one or more suppliers that engage with one or more downstream customers through service platforms or service intermediaries (Breidbach et al., 2015). The service supply chain is distinct from goods-centric supply chains (Ellram et al., 2004), and is increasingly becoming more strategic, leveraging interdisciplinary thinking as part of the service dominant (SD) logic (Lusch et al., 2006, 2007; Lusch, 2011; Vargo and Lusch, 2004; Vural et al., 
2017). S-D logic views goods as transmitters of embedded knowledge and skill, just as one would think of stand-alone services, being indicative of services as a higher-order concept (Maas et al., 2014).

A service supply chain can be defined as "the network of suppliers, service providers, consumers and other supporting units that performs the functions of transaction of resources required to produce services; transformation of these resources into supporting and core services; and the delivery of these services to customers" (Baltacioglu et al., 2007, p. 112). We adopt this definition in the current study. This is also in line with Lusch et al. (2010) and Sampson and Spring (2012), who define service supply chains as institutionalized configurations of one or more service intermediaries working with one or more service customers within a single supply chain.

S-D logic classifies resources into two types: operand resources and operant resources (Lusch et al., 2007). Operand resources are tangible and static, and only become of value if an action is performed upon them; raw materials serve as an example. In contrast, operant resources are intangible and dynamic, and can be used to act on operand resources; examples include knowledge and skills (Lusch, 2011; Tokman and Beitelspcher, 2011). Within this context, S-D logic argues that supply chains are value co-creation networks, and that different actors need to apply and integrate different types of resources (Vargo and Lusch, 2011; Lambert and Enz, 2017).

Relying on S-D logic, Richey et al. (2011) identify four basic organizational operant resources in the global marketplace, including two internal resources of customer orientation and service culture, as well as two external resources of collaborative communication with service suppliers and effective governance mechanisms; the authors find collaborative communication to have a positive relationship with global market performance. Along similar lines, Madhavaram and Hunt (2008) propose that operant resources are at the heart of competitive advantage and performance, and follow a hierarchy of basic, composite, and interconnected types. As one moves higher in the hierarchy, the resources become increasingly interconnected and more difficult for 
competitors to acquire or develop, thus leading to increased sustainable competitive advantages (Madhavaram and Hunt, 2008).

\subsection{Three flows in e-commerce supply chain management}

Mentzer et al. (2001, p.4) define a supply chain as consisting of "all the upstream and downstream flows of products, services, finances and information from the ultimate supplier to the ultimate customer." As such, the management of flows related to information, logistics and finance can be considered as the basic component of ecommerce supply chain management activities (Kim et al., 2014).

Along similar lines, Rai et al. (2006) suggest that supply chain integration encompasses the integration of information flows, which require supply chain partners to share information and develop globally optimal plans. Requirements for the integration of logistics flows include the optimization of staging and material flows, while the integration of financial flows, which are interdependent with the other activities, rely on optimal ordering policies and ensuing deliveries.

Information flow integration can be defined as the extent to which operational, tactical, and strategic information is shared between a focal firm and its supply chain partners (Rokonuzzaman, 2018). The biggest advantage of e-commerce activities over traditional business activities is that in the e-commerce environment, enterprises use modern information technology to make the flow of information more efficient. Through communication with customers, establishing customer profiles and cooperating with customers, companies can obtain targeted, content-specific and valuable market information, which can represent an important basis for various business decisions of the company (Nguyen and Sidorova, 2018).

Logistics flows refer to the physical distribution activities of goods from the origin of the raw material to the final consumers. It also includes the reverse flows of goods returns from consumers to the e-commerce platform. Given the criticality and complexity 
of this type of flow, the presence of third-party logistics providers constitutes a sound prerequisite for the development of effective e-commerce.

Financial fluidity is "the degree to which financial flows between a focal firm and its supply chain partners is driven by workflow events" (Rai et al., 2006, p. 231). It is an indispensable means to realize e-commerce transaction activities. In e-commerce, banks enable the financial flows between manufacturing companies, commercial enterprises and consumers, and thus play a pivotal role. Whether banks can effectively implement electronic payment or refunds has become key to the success of e-commerce (Kabango and Asa, 2015).

Among the three flows, information flows form the basis for both logistics and financial flows (Shaw, 2000). Without information flows, logistics and financial flows cannot operate effectively. Integration between the three flows can be accomplished via information technology (IT). As such, Rai et al. (2006) propose that IT infrastructure integration for SCM is a lower-order capability that can be leveraged to develop a higherorder process capability for the integration of supply chain processes (e.g., information and logistics flows), which can then lead to significant and sustained gains in firm performance. This idea is similar to the notion reflected in operand and operant resources as part of the S-D logic (Lusch, 2011).

Although the three flows have been mentioned frequently by traditional SCM scholars (Mentzer et al., 2001; Christopher, 2016; Coyle et al., 2017), either separately or in a combined manner, the intrinsic links between the three flows and how they are best combined to provide SCM services within the context of e-commerce, has been neglected. This is despite the fact that the coordination of the three flows has been described as imperative (Lee and Ng, 1997; Singhal and Singhal, 2012), also from the perspective of material flow theory (Hou et al., 2017). Scholars also lack an understanding of the financial flows in particular, an observation made by Maas et al. (2014), who find that existing research tends to put emphasis on information and logistics flows, with less attention being paid to the financial flows. Furthermore, Paredes et al. 
(2014) carry out a literature review on the application of S-D logic in an e-commerce context, and conclude that research in this domain is scarce. This observation, coupled with the limited research into the three flows, especially within an e-commerce context, makes this area ripe for further investigation. Overall, the gaps among the research streams are obvious: there is limited research on the relationships of the three flows, and there is limited researches on the S-D logic within the context of e-commerce.

\title{
6. Research Methodology
}

Given the limited research on S-D logic in e-commerce SCM, as well as the relatively few explorations on the integration of the three flows in SCM, a multiple case study method was adopted in this research. We follow commonly accepted standards for conducing case studies in the operations management literature to ensure rigor (Eisenhardt, 1989; Stuart et al., 2002; Voss et al., 2002).

\subsection{Case selection}

We approached 12 cross border e-commerce enterprises after participating in a crossborder e-commerce industry conference, and finally selected four companies as our case companies: OSell, Zongteng, BizArk and Linca. These companies were chosen based on a theoretical sampling approach, which had as its objective that the four firms are at different levels of service capabilities and supply chain relationship qualities, as shown in Figure 1. The detailed measurements for these two constructs are provided in Section 5.4. All four companies are leading e-commerce firms in China that operate across borders. The firms provide end-to-end cross border e-commerce services, making them good exemplars for this research. Table 1 provides some basic information about the four companies.

\author{
Insert Table 1 Here \\ Insert Figure 1 Here
}




\subsection{Data Collection}

Data were collected via multiple means, including semi-structured interviews with the four companies' managers (both senior and mid-level management), site visits, internal corporate documents, official public reports and other internet resources. These multiple sources of data enabled triangulation (Eisenhardt, 1989).

The research team interviewed five managers during the visit at Osell; five managers during two visits at Zongteng; six managers during the visit at BizArk; and five managers during two visits at Linca (details are provided in Table 2). The majority of interviewees were interviewed more than once to obtain additional information, and to ensure clarity and understanding; in total, we carried out 41 interviews. The interviews were conducted in Chinese Mandarin and the average length was about one hour. The interviewees' job titles ranged from vice present and director to mid-level managers. During the process of investigation and interview, the researchers managed to acquire information concerning the historical development, ties with suppliers and customers, as well as the firm's overall operations and business models.

The interview protocol consisted of four parts: basic information of the case companies; resources for providing SCM services; SCM service capabilities; and supply chain relationship quality. A list of interview questions is shown in the Appendix 1.

\section{Insert Table 2 about here}

\subsection{Data Analysis}

After data collection, the data were coded and analyzed. Within-case analysis was first conducted via axial coding, followed by cross-case analysis to compare the four cases. Coding was done in an iterative fashion, leveraging both the interview transcripts and secondary data. This process led to clarification and, on occasion, redefinition of the constructs and discussion of the evidence. We reached consensus on all constructs before calling the process stationary. Microsoft Excel was utilized to analyze both the semi- 
structured interview data and the secondary data (Miles et al., 2013) for data reduction and coding. Specifically, each case was coded in Excel, with the codes then being further extracted and compared across the cases in a separate Excel sheet.

According to the procedure delineated by Miles and Huberman (1994), we commenced with the within-case analysis for each of the four companies. First, we traced the history and development of the companies, as well as their lines of business (Li et al., 2012). Second, we developed a broader understanding of supply chain operand and operant resources, being reflected in information, logistics and financial flows at the four companies (Maas et al., 2014). Third, we identified supply chain service capabilities (Madhavaram and Hunt, 2008) generated by the three flow of resources through the application of S-D logic. And fourth, we captured the outcome generated by services capabilities and reflected in supply chain relationship quality.

Cross-case analyses were then carried out in order to identify patterns in different settings, and to increase the external validity of the findings. As such, we first employed "clustering" data analysis for the supply chain service capabilities at the case level. Second, we compared the four cases and linked the findings to the literature. And third, we validated our results by performing Yin's (2013) four tests (see details in Table 3).

\section{Insert Table 3 about here}

\section{Case description}

\subsection{Osell}

Osell was founded in July 2009, and began to set up an end-to-end service for crossborder e-commerce, such as the "Fulfillment by Osell (FBO) service", which includes product certification, storage, shipment declaration, inspection and quarantine, international logistics, customs declaration, taxation, overseas logistics, sorting and loading, and unloading activities. Osell has developed into the largest cross-border ecommerce trading platform in China. Osell set up their online sales channels as 
dinodirect.com, 18985.com and Osell APP, providing product data processing, global marketing, order management, multinational online customer service, global warehousing and logistics, cross-border trade settlement, and business social media services. In December 2017, the company launched the blockchain project to explore the potentials of the new technology in its cross-border e-commerce operations for enhancing traceability and improving trust. Osell built overseas warehouses in Europe and the Americas in 2009, and in April 2016 the first overseas cross-border e-commerce industrial park was launched in Dubai. Overall, Osell operates more than 20 overseas warehouses and has about 1,000 employees worldwide.

Osell has more than ten branches around the world, located in Russia, the United States, Canada, Australia, India, and Brazil, among other countries; its businesses cover more than 200 countries and regions. It serves nearly 190 thousand small- and mediumsized enterprises (SMEs) around the world, with an annual import and export value of 3 billion US dollars.

\subsection{Zongteng}

Zongteng was founded in November 2007. The company's office and storage area exceeds 100,000 square meters, and the number of daily orders processed amounts to about 50,000, with over 1,700 employees. In 2016, the total sales volume of the company was more than 17 billion RMB (over 2.4 billion US dollars at the average exchange rate in 2016). Zongteng has developed diversified and integrated operation patterns with a focus on cross-border e-commerce, integrating product research and development (R\&D), purchase, sales, storage, logistics, client service and system R\&D. The company has invested equal effort in both third-party e-commerce platforms (e.g., eBay, Amazon and Alibaba) and self-constructed business-to-consumer (B2C) platforms (www.tmart.com). In addition, it stepped up their development in export businesses as well as their professional logistics services. By the end of 2017, Zongteng had built procurement bases in Shenzhen, Guangzhou, Yiwu and Hong Kong. It further established 14 warehouses, 
including five in the United States, three in the United Kingdom, two in Germany, two in Japan, one in Australia, and one in Taiwan.

\subsection{BizArk}

BizArk was established in 2006, offering a complete set of overseas marketing solutions customized for Chinese enterprises, including overseas marketing analysis, ecommerce platform services, multi-channel marketing and operational support. The company set up e-stores on popular e-commerce platforms, such as Amazon, Newegg, Rakuten, eBay, Houzz, Sears, Wish, and Overstock, among others. In 2009, BizArk elevated its investment in technology and, since then, has developed a state of the art IT system. From 2015 to 2017, BizArk carried out overseas warehouse operations in the United States, Germany, Japan and Spain.

BizArk operates two businesses models. The first business model consists of joint operational support, which involves running the brand and collecting commissions from customers. In this model, BizArk helps factories build brands and channels abroad by relying on the infrastructure of Amazon, eBay and other foreign channels. In 2016, about 60 brands were operating in Amazon Europe and Amazon United States, with an annual sales volume of about 10 million US dollars. The second business model is consulting, providing staff training, building cross-border e-commerce business teams, and business system services for traditional international trading enterprises that want to enter into cross border e-commerce.

\subsection{Linca}

Linca was established in October, 2014. Linca's businesses include marketing, crossborder B2B, B2C, incubation and support. Linca set up the online sales channels of Nitago.com, Nitago app, Taipingou app, and Nitabang app. It mainly focuses on maternal

and infant health care, computer, communication, consumer electronics, daily use cosmetics, and fresh food products. In 2015, the total transaction volume exceeded 476 
million US dollars. The monthly transaction volume has exceeded 400 million RMB and over 5,000 businesses have joined as online/offline distribution partners. In September 2015, Linca began to build logistics parks, bonded warehouses (for imports), and overseas warehouses (for exports). Linca has nearly 3 million square meters of warehouses, including 350,000 square meters of free trade zone bonded warehouses, and cross-border commodity exhibition and trading centers, serving more than 2,000 global high-quality brands marketed in more than 60 countries.

The milestones of each firm in terms of their activities related to the three flows are shown in Table 4. In the following, we summarize key information relevant for the development of the four companies.

\section{Insert Table 4 about here}

\section{Cross case analysis and discussion}

This section discusses the findings of the cross-case analysis through a comparison with the literature. In order to answer the research questions posed above, a framework is proposed in Figure 2 and four sets of propositions are developed. We find that the interaction of the operand and operant resources from the three flows can generate enhanced service capabilities, which in turn contribute to supply chain relationship quality in terms of trust improvement/commitment, risk mitigation, and consumer satisfaction. Our findings support the argument that capabilities of a company are enabled by processes and resources (Martin and Eisenhardt, 2000), with operant resources being able to be used to act on operand resources to co-create customer-driven supply chain networks (Lusch, 2011; Vargo and Lusch, 2011).

We first discuss the capabilities generated by information flow related resources, followed by the services capabilities generated by combining the three flows (in pairs or in unison). We then discuss the relationships among the three flows, and finally delineate the relationship between supply chain service capabilities and relationship quality. 


\section{Insert Figure 2 about here}

\subsection{Capabilities generated from information flow related resources}

We identified supply chain service capabilities to be generated by the combination of various internal resources supporting the three flows (processes) of information, logistics and capital, with information flows playing a fundamental role. Table 5 describes the service capabilities that are generated from information flow related resources. Based on the hierarchy of operant resources and strategy (Madhavaram and Hunt, 2008), we divide information flow related operant resources into three aspects, which are internal orientation, market orientation, and knowledge management orientation-we discuss them in further detail below. The operand resource for information flow is the IT architecture.

\section{Insert Table 5 about here}

First, the management of information flows enables e-commerce firms to pay better attention to their internal organisational structure. In order to respond to the rapidly changing and dynamic market, the interviewed firms tend to adjust their organisational structures from a mechanistic (centralised and hierarchical) to an organismic framework (highly connected, flat and decentralized). For example, Zongteng has changed their internal structure to be more effective by transforming traditional functions (operations, finance, human resources and IT) into service platforms, with some of the product divisions becoming small independent companies to adapt to markets better. As Tushman and Nadler (1978) point out, an organismic structure would promote the information processing capacity, because such structure is relatively independent of any one individual, and is less sensitive to information overload or saturation compared to a more limited structure. Due to the advantages of organismic structures, almost every employee is empowered with a certain level of decision-making authority, which can provide for 
better responsiveness and ensuing better service quality for customers.

In addition, the information from the supply chain helps the firm detect business opportunities. For example, Osell provides market information to their employees to encourage internal entrepreneurship. By doing so, Osell can manage their supply chain more effectively in order to provide better customer service. The quotes from BizArk and Linca (in Table 5 a, internal operations) also suggest that their employees have more power to make decisions. Based on these observations, we propose the following:

Pla. Information flow management urges e-commerce firms to form a decentralised organisational structure in order to meet information processing requirements and encourage internal entrepreneurship, which enables these firms to respond to markets in a more timely manner.

Second, information flow management provides e-commerce firms useful customer information to enable a better customer-orientated service delivery. As such, a better understanding of targeted buyers' preferences can be obtained, which enables a continuous creation of customer value (Narver and Slater, 1990). We also noted that the case firms collect customer information (e.g., gender, age, region, purchase habits) from their e-commerce platforms to generate intelligence about current and future needs of targeted customers. Cross-border e-commerce firms use the data to generate a "user portrait" to inform market and product development. This supports similar arguments by Teece (1998) and Grawe et al. (2009) in that information exchange enables the development of capabilities, with customer orientation being positively related to service capabilities. Table 5 provides supporting quotes from the four organizations, illustrating the application of market data for product selection, procurement, marketing channel selection and inventory preparation. Based on this insight generated, we propose the following: 
P1b. Market information management drives cross-border e-commerce firms to promote product development and accelerate customer response speed, enabling a better customer orientation.

Third, technology used in information flow management accelerates trade and provides added service capabilities for customers. Barrett and Konsynski (1982) state that information technology that includes computer hardware, software, and communication systems, enables firms to deal with time-consuming processes more rapidly, enabling the transformation of data into useful information. From our case companies, we find that Osell uses the Yueshang APP to communicate with customers anytime and anywhere. Zongteng also helps customers to optimise sales by its information processing technology. BizArk uses the Global Export Easy software to interact directly with stakeholders, allowing overseas customers to indicate their purchasing intentions on the basis of a full understanding of the e-tailers. Finally, Linca provides small business customers with inventory planning services, automatic ordering and automatic replenishment services, as well as training services.

Information technology adoption enables the establishment of smooth communication channels with customers. Further, the use of information technology (operand resources) is positively associated with inter-firm learning (Rebolledo and Nollet, 2011) to facilitate the efficient transfer, storage and integration of knowledge, i.e., operant resources (Grant and Baden-Fuller, 1995). The information sharing among supply chain partners generates new knowledge and facilitates the coordination and adjustment of business processes to increase the service for customers. We therefore propose the following:

P1c. Information flow management with the support of technology can achieve data-toinformation conversion, generating knowledge to improve supply chain service capabilities (e.g., provide training or knowledge). 


\subsection{Service capabilities generated from combining the three flows in pairs or in unison}

There are many studies demonstrating that information sharing among supply chain partners improves competitiveness and effectiveness of supply chains. Information flows, which have priority over logistics flows (Graham and Hardaker, 2000) and financial flows, are the foundation for any effective supply chain and have thus the ability to reduce uncertainty that can make cross-border e-commerce supply chains risky and reactive (Ellram et al., 2004). In this section we discuss the services capabilities generated from combining logistics and information flows, and from combining financial and information flows.

\subsubsection{Service capabilities generated from combining information and logistics flow $(\mathrm{I}+\mathrm{L})$ related resources}

Table 6 describes the service capabilities generated from combing resources related to information and logistics flows. First, by combining relevant operand and operant resources, logistics visualization can be achieved, enabling the traceability of goods by technologies such as RFID. Technologies like these have been adopted by all four firms in our sample. Second, firms may be able to identify process re-engineering opportunities by utilizing different kinds of warehouses as operand resources, combined with the knowledge of the end-to-end logistics design and associated market information. With this insight, value-added services can be provided to customers. Third, equipped with operand resources of packaging solutions, an appropriate IT architecture, automation and operant resources of logistics routing optimisation, and automated system knowledge, cross-border e-commerce companies can provide integrated solutions for customers, yielding more effective logistics operations, enhanced logistics services and better control of logistics risks. For example, "Full Performance" service for customers provided by Osell facilitates processes in traditional foreign trade and provides clients with best price evaluation abilities, helping Chinese companies sell overseas with a professional team, 
one-stop service, monitoring systems, and integrated resources. Such new capabilities generated by the combination of resources related to information and logistics flows can provide more personalised services for customers. Thus, we propose the following: $P 2 a$. The combination of resources related to information and logistics flows generate new supply chain service capabilities in the form of logistics visualisation, logistics effectiveness and logistics process re-engineering.

\section{Insert Table 6 about here}

\subsubsection{Service capabilities generated from combining information and financial flows} $(\mathbf{I}+\mathbf{F})$

Table 7 describes the service capabilities generated from combing resources related to information and financial flows. We find that all four case companies rely on third-party financial services providers to carry out basic financial flow services, which reflect their capability in regards to financial network mapping. Together with the information flow, Zongteng and Osell can provide supply chain finance services based on the sharing of financial information systems with customers. For example, Zongteng collaborated with iPayLinks to design innovative financial processes and provide supply chain financial products/services. The companies can also manage their financial risks through the two flows. We therefore propose the following:

$P 2 b$. The combination of resources related to information and financial flows generates new supply chain service capabilities in the form of supply chain finance.

\section{Insert Table 7 about here}

\subsubsection{Service capabilities generated from combining the three flows in unison $(I+L+F)$}

Table 8 describes the service capabilities generated from combing the resources related to information, financial and logistics flows. We find that Osell is the only one in our 
sample that combines these three flows, thus enabling them to create innovative solutions based on all available operand and operant resources embedded in the three flows. As such, Osell launched its overseas cross-border e-commerce industrial park in Dubai in 2016, which allows Osell to provide logistics finance services based on the visualization of supply chains and the presence of overseas warehouses. Osell joins the SilkChain, a digital chain of international trade enabled by blockchain technology, providing global customers with services such as supplier identification, access to overseas warehousing/logistics, import/export advisory services, insurance services, and epayment services. At the same time, Chinese suppliers can query the buyer's distribution channels, capital status, and business reputation on the blockchain, realize product sales in the local market, and obtain customer response information to find a stable export market at a low cost. Based on these findings we propose the following:

$P 2 b$. The combination of resources related to information, logistics and financial flows generates new supply chain service capabilities (e.g., finance risk control) and other innovative solutions.

\section{Insert Table 8 about here}

\subsection{The relationships among the three flows}

Table 4 captures the business milestones for the four firms, and delineates their information, logistics and financial flows systems. We observe that the cross-border ecommerce system interweaves the three flows. As illustrated in Table 4, we find that the four case companies develop their businesses according to the following sequence: commencing with the IT infrastructure, logistics systems are built next, with financial services being the final aspect being addressed.

As such, overall information flow management is the cornerstone of an enterprise and supports the other two flows based on the data that is made accessible and visible. Without information or data, the risks of providing logistics and financial services would 
be too great. From the view of an e-commerce platform, the uncertainty of credits coming from both suppliers and customers, combined with a potentially poor credit appraisal system in the early stages, represents large transactions risks to cross-border e-commerce (Fu and Noche, 2012). As cross-border e-commerce enterprises are gradually developing into comprehensive e-commerce platforms, developing information processing capabilities is essential, as it reduces the risk for cross-border e-commerce enterprises.

The logistics flow from upstream to downstream supply chain entities needs to be supported by information flows. In Table 6, we find that the information flow can affect the effectiveness of logistics operations as it pertains to the management of distribution, logistics, warehouses, and the selection of transportation modes, among others. For example, Osell can automatically match shipments with the most suitable logistics company in different countries based on data analysis. Zongteng uses information to optimize the selection and sources of products, to plan warehouse layout and automatically decide sorting and packaging routes in the warehouse. In addition, Linca achieved traceability by launching an information platform with partners. Finally, BizArk helps sellers to improve efficiency in managing the orders through IT systems. Similar to Prajogo and Olhager (2012), who suggest that the intensity of information sharing has a positive relationship with logistics integration, our cases provide support for such relationship. Based on these findings we propose the following:

P3a. Information flow management is the cornerstone of SCM and supports the logistics and finance flows.

With the support of information flow management, firms tend to combine information and capital management in order to implement supply chain finance and manage financial risks (Tables 7 and 8). As Zeng and Rossetti (2003) point out, logistics controls a significant amount of assets, and thus has a direct impact on the financial flow. Furthermore, financial flows can guarantee the smooth operation of logistics in turn (Lee and Chang, 2007). Thus we propose the following: 
P3b. With the support of information flows, logistics flows have a direct impact on financial flows and vice versa, i.e. logistics and financial flows co-influence each other.

\subsection{The relationship between supply chain service capabilities and supply chain relationship quality}

Table 9 summarizes our observations in regards to supply chain relationship quality (low, medium or high) for the four cross border e-commerce companies. It can be seen that the scores on trust improvement and commitment for Osell is high, for Zongteng it is medium, and for both BizArk and Linca they are low. The score for risk mitigation for Osell is high, with Zongteng, Linca and BizArk receiving medium risk mitigation scores. For customer satisfaction, the score is also high only for Osell, low for Linca, and medium for the other two firms. Thus overall, Osell's relationship quality can be considered as high, Zongteng's as medium, BizArk's as medium to low, and Linca's as low. We offer further insights into the components of relationship quality in the following.

First, trust is the perception of confidence in the exchange partner's reliability and integrity (Morgan and Hunt, 1994). We measure this through the attainment of government certifications demonstrating good customer service, as well as venture capital investment the firms obtained. Osell gained trust from investors, foreign market governments, and Chinese governments, which shows a relatively high level of trust. Zongteng also obtained the status of "e-commerce model enterprise," which is certified by the Ministry of Commerce of China, in addition to receiving 100 million Yuan in investments in 2018. The trust levels of other two companies are comparatively lower than the first two companies. BizArk also obtained investments and the certification, but the certification is only at a provincial level. Linca has not obtained investments by others, which shows a lower trust by governments.

Through the analysis as summarized in Table 5, we find that a high level of supply chain service capabilities generated by resources related to information flows have a positive effect on trust and commitment by customers. The results are similar to the 
argument by He et al. (2014), in that service capability has a positive effect on a firm's level of customer trust and integration. However, our research objectives are different from theirs (they focused on manufacturing firms). We therefore propose the following.

P4a. Greater levels of supply chain service capabilities generated by the resources related to the three flows by cross-border e-commerce firms improve trust and customer commitment.

\section{Insert Table 9 about here}

Second, we consider risk mitigation as an important dimension to measure supply chain relationship quality. Risk is the probability and negative consequence of an event (Jia and Rutherford, 2010). The sampled cross border e-commerce companies generally focus on logistics risk, credit risk, financial risk, customs, tax and legal risks, as well as policy risk. For example, Osell uses customer credit ratings on the platform and an antifraud system to prevent credit risk, and established a special centre to prevent policy risks. As such, risk mitigation prevention measures by Osell are stronger than these measures at any of the other three firms. These firms obtained medium scores in our ratings, with all of them providing similar risk mitigation services. We therefore propose the following.

P4b. Greater levels of supply chain service capabilities generated by resources related to the three flows by cross-border e-commerce firms mitigate trading activity risks for the parties involved.

Third, we measure relationship quality from the views of customers and tap into their satisfaction. We determined customer satisfaction by searching the internet, referring to the consumer evaluation scores by the third-party evaluation site "sitejabber" (https://www.sitejabber.com/), and by summarizing the buyers' comments. With this approach, we found customer satisfaction towards Osell to be rated with 4 stars out of 5; 
this is a high rating, substantiated by mostly positive customer comments. BizArk and Zongteng (Tmall received 3 out of 5 stars at sitejabber) received both positive and negative comments from various third party platforms, while Linca's consumers always complained about customer traffic in the offline stores due to large volumes of customers, yielding a low rating. Hence, we can conclude that a high level of service capabilities generated from three flow related resources enables firms to provide more and better service to customers.

P4c. Greater levels of supply chain service capabilities generated by resources related to the three flows by cross-border e-commerce firms increase customer satisfaction.

Overall, supply chain capabilities are the building blocks for supply chain strategy and a source of competitive advantage (Morash, 2001). As to service capability, Zhang and Chen (2008) point out, in a mass customization context, that a firm that succeeds in enhancing service capabilities will have more opportunities to gain advantages over its rivals, since it represents a significant chance for it to cater to the customers' preferences. Since the high level of service capabilities offered to customers can improve trust, risk mitigation and customer satisfaction, these capabilities can improve the overall supply chain relationship quality. Based on above arguments and findings, and integrating P4a, $\mathrm{P} 4 \mathrm{~b}$ and $\mathrm{P} 4 \mathrm{c}$, we offer the following integrative proposition.

P4. Greater levels of supply chain service capabilities generated by resources related to the three flows by cross-border e-commerce firms increase supply chain relationship quality.

\section{Conclusion}

Cross-border e-commerce is becoming increasingly popular around the world. In practice, cross-border e-commerce companies are building on their existing business foundation, and transitioning from a product-dominant logic to a service-dominant logic (Lusch et 
al., 2006, 2007; Vargo and Lusch, 2004). However, research questions, such as what services cross-border e-commerce firms can provide and how cross-border e-commerce firms can improve supply chain relationship quality through the management of the three flows, remain unanswered. Furthermore, the relationship between the three flows of information, logistics and finance has rarely been discussed comprehensively since the founding of the SCM discipline. In order to fill these shortcomings and answer the noted research questions, we conducted a multiple case study and adopted the service dominant logic in interpreting the findings. We proposed a framework with four sets of propositions, which are reflective of the interaction between operand and operant resources embedded in the three flows, able to generate enhanced supply chain service capabilities, and in turn able to contribute to supply chain relationship quality in terms of trust improvement/commitment, risk mitigation and consumer satisfaction. Our research makes significant theoretical and managerial contributions, which are further discussed in the following.

\subsection{Theoretical contributions}

We make the following theoretical contributions to the SCM literature. First, we propose a framework that encapsulates the interactions and combinations of the resources related to the three flows as being fundamental for the development of supply chain service capabilities, which in turn contribute to supply chain relationship quality, as reflected in trust improvement/commitment, risk mitigation and consumer satisfaction. Our findings are aligned with the S-D logic in that supply chains can be viewed as value co-creation networks that can promote knowledge and capability (operant resources) growth, as well as exchange amongst network members via operand resources related to the three flows (Tokman and Beitelspcher, 2011; Vargo and Lusch, 2011). We are the first to map out the operand and operant resources embedded in the three flows and identify supply chain capabilities generated from combining these resources. 
Second, we are the first to delineate clearly with cross-border e-commerce industry cases the relationship between the three flows of information, logistics and finance. For cross-border e-commerce companies, the most fundamental requirement for the interaction is the development of information technology. Through visualization and perceptualization of the data, reliable projections and beneficial solutions can be provided for future development. One of the key benchmarks for the upgrading of cross-border ecommerce companies is the establishment of a sophisticated logistic system based on the information flow, which enables the companies to build overseas bonded warehouses, obtain import/export customs clearance inspections, integrate logistic systems, and enable sound and effective financial processes. Our analysis and illustration of the basic hierarchy pertaining to the three flows in cross-border e-commerce companies is helpful for the future development of this industry in China.

Third, we are the first to propose the fundamental notion that cross-border ecommerce companies/platforms are providing SCM services. Hence, this kind of platform provides an ideal setting for us to gain a deeper and better understanding of the very concept of SCM (e.g., Mentzer et al., 2001), which tends to be generally described as the management of the three flows connecting upstream and downstream organisations. It is shown that cross-border e-commerce companies' core competence lies in their capability to provide supply chain services reflected in the management of the three flows. We thus suggest that the key issue in future company development should be more about the ability to effectively provide clients with plausible solutions, rather than the mere transition from a product-dominant logic to a service-dominant logic (Ostrom et al., 2010).

\subsection{Managerial contributions}

Our research has important managerial implications. The service-dominant logic provides a new operating philosophy of emphasising the services customers' needs, distinguishing operand from operant resources. We applied this theory to the cases sampled to illustrate this logic, and explored the operant capabilities/resources generated from the operand 
resources of the three flows. Other cross-border e-commerce companies can learn from our propositions and arguments. First, in terms of changing their operating mind-set towards co-creating supply chain networks in order to provide better services to customers, companies should follow the sequence of enhancing information flow capability first, then logistics and finally financial capabilities. Second, cross border ecommerce companies can more innovatively combine and re-arrange their resources related to the three flows in order to design new and tailored services for their customers. Third, these companies need to realise that their relationship quality with their customers hinges on the three aspects of trust, customer risk mitigation, and customer satisfaction.

\subsection{Limitations and future research directions}

First, although we approached 12 cross-border e-commerce companies and eventually selected four based on the two constructs of supply chain service capabilities and supply chain relationship quality, the sample size is small. A large-scale sample survey should be conducted in the future to test the model developed in this study. Second, the information acquired from the researchers' field visits might not be sufficient to cover all the complexities of cross-border e-commerce, thus longitudinal studies are needed to trace the development of cross-border e-commerce firms over time; this will offer more insights into factors affecting the relationships stipulated in the model.

Third, the measurements or indicators for supply chain relationship quality are subjective and can be improved to be more objective in a survey project. Fourth, our research focuses on Chinese cross-border e-commerce companies, potentially limiting the findings to this geographic region; future research in different geographic and cultural contexts are therefore needed. Finally, even within China, the varied ownership patterns of e-commerce companies may allow for differentiated government incentives, thus making it a complex setting. As such, in the present research, all four companies were private Chinese firms, as opposed to Western companies operating in China, such as Amazon. Future research is encouraged to investigate dynamics inherent to ownership 
structures not investigated here (in particular Amazon), and compare the findings to the ones obtained herein.

\section{References}

Ayala, N.F., Gerstlberger, W. and Frank, A.G. (2019). "Managing servitization in product companies: the moderating role of service suppliers". International Journal of Operations \& Production Management, 39(1), 43-74.

Baltacioglu, T., Ada, E., Kaplan, M. D., Yurt and, O., \& Cem Kaplan, Y. (2007). “A new framework for service supply chains”. The Service Industries Journal, 27(2), 105124.

Barrett, S. and Konsynski, B. (1982), "Inter-organization information sharing systems", MIS Quarterly, 6 (4), 93-105.

Baruca, A. and Zolfagharian, M. (2012). "Cross-border shopping: Mexican shoppers in the US and American shoppers in Mexico". International Journal of Consumer Studies, 37(4), 360-366.

Bovet, D., and Martha, J. (2000). "Value nets: reinventing the rusty supply chain for competitive advantage". Strategy and Leadership, 28(4), 21-26.

Breidbach, C., Reefke, H. and Wood, L. (2015). "Investigating the formation of service supply chains". The Service Industries Journal, 35(1-2), 5-23.

Christopher, M. (2016), "Logistics \& Supply Chain Management", 5th edition, Pearson Education, Harlow, England.

Coyle, J.J., Langley, C.J., Novack, R.A. and Gibbson, B.J. (2017), "Supply Chain Management: A Logistics Perspective", 10 th edition, Cengage Learning, Boston.

Eisenhardt, K.M. (1989), "Building theory from case study research", Academy of Management Review, 14 (4), 532-550.

Ellram, L. M., Tate, W. L. and Billington, C. (2004), "Understanding and managing the services supply chain", Journal of Supply Chain Management, 40(3), 17-32.

$\mathrm{Fu}, \mathrm{H}$. and Noche, B. (2012), "Integration of truncated distributions in exponential family with simulation models of logistics and supply chain management", Journal of Physiology, 2012(2), 385-93.

Gang, L. (2017). "Research on innovation of e-commerce supply chain of agricultural products under service dominant logic". Journal of Business Economics, 03, 1219, doi: 10.14134/j.cnki.cn33-1336/f.2017.03.002 (In Chinese).

Giannakis, M. (2011). "Conceptualizing and managing service supply chains". The Service Industries Journal, 31(11), 1809-1823.

Graham, G. and Hardaker, G. (2000), "Supply chain management across the Internet", International Journal of Physical Distribution \& Logistics Management, 30(3/4), 286-295.

Grant, R. M. and Baden-Fuller, C. (1995), "A knowledge-based theory of inter-firm collaboration", Academy of Management Journal (Special Issue: Best Papers Proceedings), 17-21.

Grawe, S. J., Chen, H. and Daugherty, P. J. (2009), "The relationship between strategic orientation, service innovation, and performance", International Journal of Physical Distribution \& Logistics Management, 39(4), 282-300.

Gunasekaran, A., and Ngai, E. W. (2004). "Information systems in supply chain 
integration and management". European Journal of Operational Research, 159(2), 269-295.

Hameri, A. and Hintsa, J. (2009). "Assessing the drivers of change for cross-border supply chains". International Journal of Physical Distribution \& Logistics Management, 39(9), 741-761.

He, Y., Keung Lai, K., Sun, H. and Chen, Y. (2014), "The impact of supplier integration on customer integration and new product performance: The mediating role of manufacturing flexibility under trust theory", International Journal of Production Economics, 147(PART B), 260-270.

Hou, H., Chaudhry, S., Chen, Y. and Hu, M. (2017). "Physical distribution, logistics, supply chain management, and the material flow theory: a historical perspective". Information Technology and Management, 18(2), 107-117.

Inama, S., \& Sim, E. W. (2015). "The foundation of the ASEAN Economic Community: An institutional and legal profile (Vol. 5)". Cambridge University Press.

iResearch (2018). “2018 China's Cross-Border Import Retail E-Commerce Report”. Available online: http://www.iresearchchina.com/content/details8_46058.html (accessed on 25 October 2018)

Jia, F. and Rutherford, C. (2010), "Mitigation of supply chain relational risk caused by cultural differences between China and the West", International Journal of Logistics Management, 21(21), 251-270.

Johnson-Page, G. and Thatcher, R. (2001). "B2C data privacy policies: current trends". Management Decision, 39(4), 262-272.

Kabango, C. M., and Asa, A. R. (2015). "Factors influencing e-commerce development: Implications for the developing countries". International Journal of Innovation and Economics Development, 1(1), 64-72.

Kim, Y. H., Sting, F. J., and Loch, C. H. (2014). “Top-down, bottom-up, or both? Toward an integrative perspective on operations strategy formation". Journal of Operations Management, 32(7-8), 462-474.

Lambert, D.M., Cooper, M.C. and Pagh, J.D. (1998) "Supply Chain Management: Implementation Issues and Research Opportunities", The International Journal of Logistics Management, 9(2), 1-20.

Lambert, D. M., \& Enz, M. G. (2017). “Issues in supply chain management: Progress and potential". Industrial Marketing Management, 62, 1-16.

Lee, M. C. and Chang, T. (2007), "Linking knowledge management and innovation management in e-business", International Journal of Innovation \& Learning, 4(4), 145-159.

Lee, H. L. and Ng, S. M. (1997). "Introduction to the special issue on global supply chain management". Production and Operations Management, 6(3), 191-192.

Li, H., Sun, J., Li, J. and Yan, X. (2012). "Forecasting business failure using two-stage ensemble of multivariate discriminant analysis and logistic regression”. Expert Systems, 30(5), 385-397.

Lusch, R.F. (2011). "Reframing supply chain management: a service-dominant logic perspective". Journal of Supply Chain Management, 47(1), 14-18.

Lusch, R.F., Vargo, S.L., and Malter, A.J. (2006). "Marketing as service-exchange: Taking a leadership role in global marketing management". Organizational Dynamics, 35(3), 264-278. 
Lusch, R. F., Vargo, S.L., and O'brien, M. (2007). "Competing through service: Insights from service-dominant logic". Journal of Retailing, 83(1), 5-18.

Lusch, R.F., Vargo, S.L., and Tanniru, M. (2010). "Service, value networks and learning". Journal of the Academy of Marketing Science, 38(1), 19-31.

Madhavaram, S., \& Hunt, S. D. (2008). "The service-dominant logic and a hierarchy of operant resources: developing masterful operant resources and implications for marketing strategy". Journal of the Academy of Marketing Science, 36(1), 67-82.

Maas, S., Hartmann, E., \& Herb, S. (2014). "Supply chain services from a servicedominant perspective: a content analysis". International Journal of Physical Distribution \& Logistics Management, 44(1/2), 58-79.

Martin, J. A., \& Eisenhardt, K. M. (2010). "Rewiring: Cross-business-unit collaborations in multibusiness organizations". Academy of Management Journal, 53(2), 265301.

Mentzer, J. T., DeWitt, W., Keebler, J. S., Min, S., Nix, N. W., Smith, C. D., and Zacharia, Z. G. (2001). "Defining supply chain management". Journal of Business Logistics, 22(2), 1-25.

Ministry of Commerce (2015). "The development of Cross-border e-commerce". Available online: http://history.mofcom.gov.cn/?newchina... (accessed on December 01, 2018)

Ministry of Commerce (2018). "2018 China E-Commerce Development Report". Available online: https://www.sohu.com/a/233871778_353595 (accessed on June 03, 2018)

Miles, M. B., Huberman, A. M., Huberman, M. A., and Huberman, M. (1994). "Qualitative data analysis: An expanded sourcebook". Sage Publications: Los Angeles, CA, USA.

Morash, E. A. (2001), "Supply chain strategies, capabilities, and performance", Transportation Journal, 41(1), 37-54.

Morgan, R. M. and Hunt, S. D. (1994), "The commitment-trust theory of relationship marketing", Journal of Marketing, 58(3), 20-38.

Narver, J. C. and Slater, S. F. (1990), "The effect of a market orientation on business profitability", Journal of Product Innovation Management, 8(4), 20-35.

Nguyen, Q. N., \& Sidorova, A. (2018). Organizational Identification and User Responses to Online Organization Criticism. Journal of Computer Information Systems, 112.

Ostrom, A. L., Bitner, M. J., Brown, S. W., Burkhard, K. A., Goul, M., Smith-Daniels, V., ... and Rabinovich, E. (2010). "Moving forward and making a difference: research priorities for the science of service". Journal of Service Research, 13(1), 4-36.

Paredes, M. R., Barrutia, J. M. and Echebarria, C. (2014). "Resources for value cocreation in e-commerce: a review". Electronic Commerce Research, 14(2), 111136.

Prajogo, D. and Olhager, J. (2012), "Supply chain integration and performance: the effects of long-term relationships, information technology and sharing, and logistics integration", International Journal of Production Economics, 135 (1), 514-522.

Rai, A., Patnayakuni, R., and Seth, N. (2006). "Firm performance impacts of digitally enabled supply chain integration capabilities". MIS Quarterly, 30, 225-246.

Rebolledo, C. and Nollet, J. (2011), "Learning from suppliers in the aerospace industry", 
International Journal of Production Economics, 129(2), 328-337.

Richey, R. G., Hilton, C. B., Harvey, M. G., Beitelspacher, L. S., Tokman, M., \& Moeller, M. (2011). "Aligning operant resources for global performance: An assessment of supply chain human resource management". Journal of Management \& Organization, 17(3), 364-382.

Rokonuzzaman, M. (2018). "The Integration of Extended Supply Chain with Sales and Operation Planning: A Conceptual Framework". Logistics, 2(2), 8.

Sampson, S. and Spring, M. (2012). "Customer Roles in Service Supply Chains and Opportunities for Innovation”. Journal of Supply Chain Management, 48(4), 3050.

Sanchez-Rodrigues, M., Potter, D. and Naim, P. (2010). "Evaluating the causes of uncertainty in logistics operations". The International Journal of Logistics Management, 21(1).

Shaw, M. J. (2000). "Information-based manufacturing with the web". International Journal of Flexible Manufacturing Systems, 12(2-3), 115-129.

Singhal, K. and Singhal, J. (2012). "Imperatives of the science of operations and supplychain management". Journal of Operations Management, 30(3), 237-244.

Stuart, I.; McCutcheon, D.; Handfield, R.; McLachlin, R.; Samson, D. (2002) "Effective case research in operations management: A process perspective". Journal of Operation Management. 20, 419-433.

Standing, S., Standing, C. (2015) "Service value exchange in B2B electronic marketplaces", Journal of Business \& Industrial Marketing, 30(6), 723-732.

Teece, D. J. (1998), "Capturing value from knowledge assets: the new economy, markets for know-how, and intangible assets", California Management Review, 40(3), 5579.

Tokman, M., and Beitelspacher, L. S. (2011). "Supply chain networks and servicedominant logic: suggestions for future research". International Journal of Physical Distribution \& Logistics Management, 41(7), 717-726.

Tushman, M. L. and Nadler, D. A. (1978), "Information processing as an integrating concept in organizational design", The Academy of Management Review, 3(3), 613-624.

Van Heel, B., Lukic, V. and Leeuwis, E. (2011). "Cross-border e-commerce makes the world flatter", Boston Consulting Group, MA, USA.

Vargo, S., and Lusch, R. (2004). "The Four Service Marketing Myths". Journal of Service Research, 6(4), 324-335.

Vargo, S. L., and Lusch, R. F. (2011). "It's all B2B... and beyond: Toward a systems perspective of the market". Industrial Marketing Management, 40(2), 181-187.

Voss, C., Tsikriktsis, N. and Frohlich, M. (2002), "Case research in operations management", International Journal of Operations and Production Management, 22, 2, 195-219.

Vural, S., Wang, N., Navaratnam, P., and Tafazolli, R. (2017). "Caching transient data in Internet content routers". IEEE/ACM Transactions on Networking, 25(2), 10481061.

Wells, J.R., Danskin, D., and Ellsworth, G. (2018). "Amazon.com, 2018." Harvard Business School Case 716-402, August 2015 (Revised May 2018).

Xie, K., Wu, Y., Xiao, J. and Hu, Q. (2016). "Value co-creation between firms and customers: The role of big data-based cooperative assets". Information \& Management, 53(8), 1034-1048. 
Xinhuanet (2016). "Cross-Border E-Commerce to Boost Chinese Foreign Trade". Available online: http://news. xinhuanet.com/english/201601/07/c_134987430.htm (accessed on 7 October 2018).

Yin, R. (2013). "Case Study Research", fifth edition. Sage Publications: Los Angeles, CA, USA.

Zeng, A. Z. and Rossetti, C. (2003), "Developing a framework for evaluating the logistics costs in global sourcing processes: an implementation and insights", International Journal of Physical Distribution \& Logistics Management, 33(9), 785-803.

Zhang, X. and Chen, R. (2008), "Examining the mechanism of the value co-creation with customers", International Journal of Production Economics, 116(2), 242-250. 


\section{Appendix 1. Interview protocol}

1. Background information

Please introduce the background of your company, your supply chain processes and major supply chain partners. Please describe the development of your company.

2. Resources for providing Supply Chain Service

How do you provide services to your customers? What supply chain services do you provide to which supply chain partners? Which resources do you need?

3. Supply Chain Service Capabilities

How do you manage the information, logistics and financial flows in order to provide the supply chain services? What capabilities are developed for this?

4. Supply Chain Relationship Quality

How do you enhance the supply chain relationship quality? How do you measure your supply chain relationship quality? 


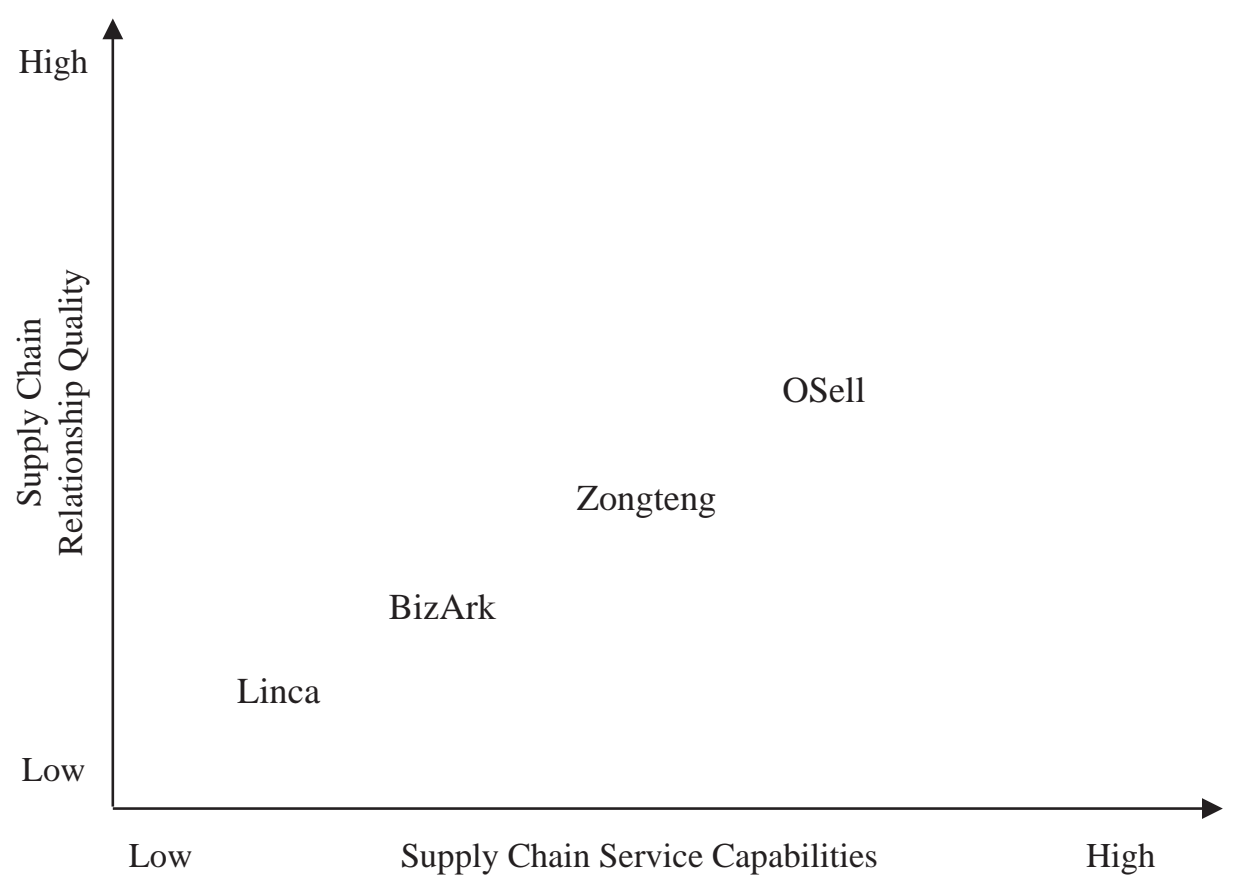

Figure 1 Sampling logic based on two dimensions

First Order Concepts:

Operand and Operant Resources

\section{Second Order Concepts:}

Three Flows
Aggregate Dimensions

- Internal orientation

- Customer orientation

- Knowledge management orientation

- Logistics routing optimisation; automated system knowledge

- Knowledge related to visualization and traceability

- End-to-end logistics knowledge

- Financial network mapping; design finance business process
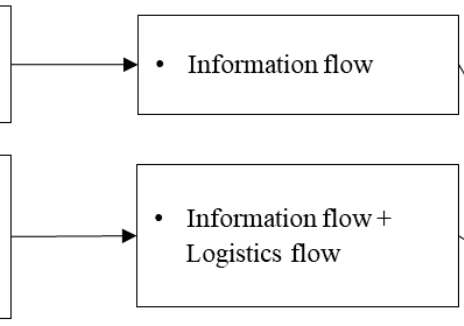

- Information flow + Logistics flow

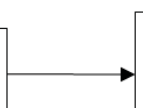

- Information flow + Financial flow

- Information flow + Logistics flow +

Financial flow Supply chain finance knowledge; risk management
knowledge; full visibility of the whole supply chain
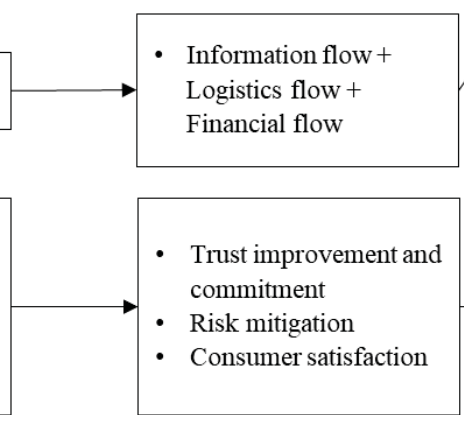

Supply Chain Service Capabilities

- Government certifications and the venture capital investment

- Approaches to manage logistics risk, credit risk, financial risk, customs, tax, legal risks and policy risk

- Consumer evaluation score, industry expert opinion

Figure 2 Data structure 


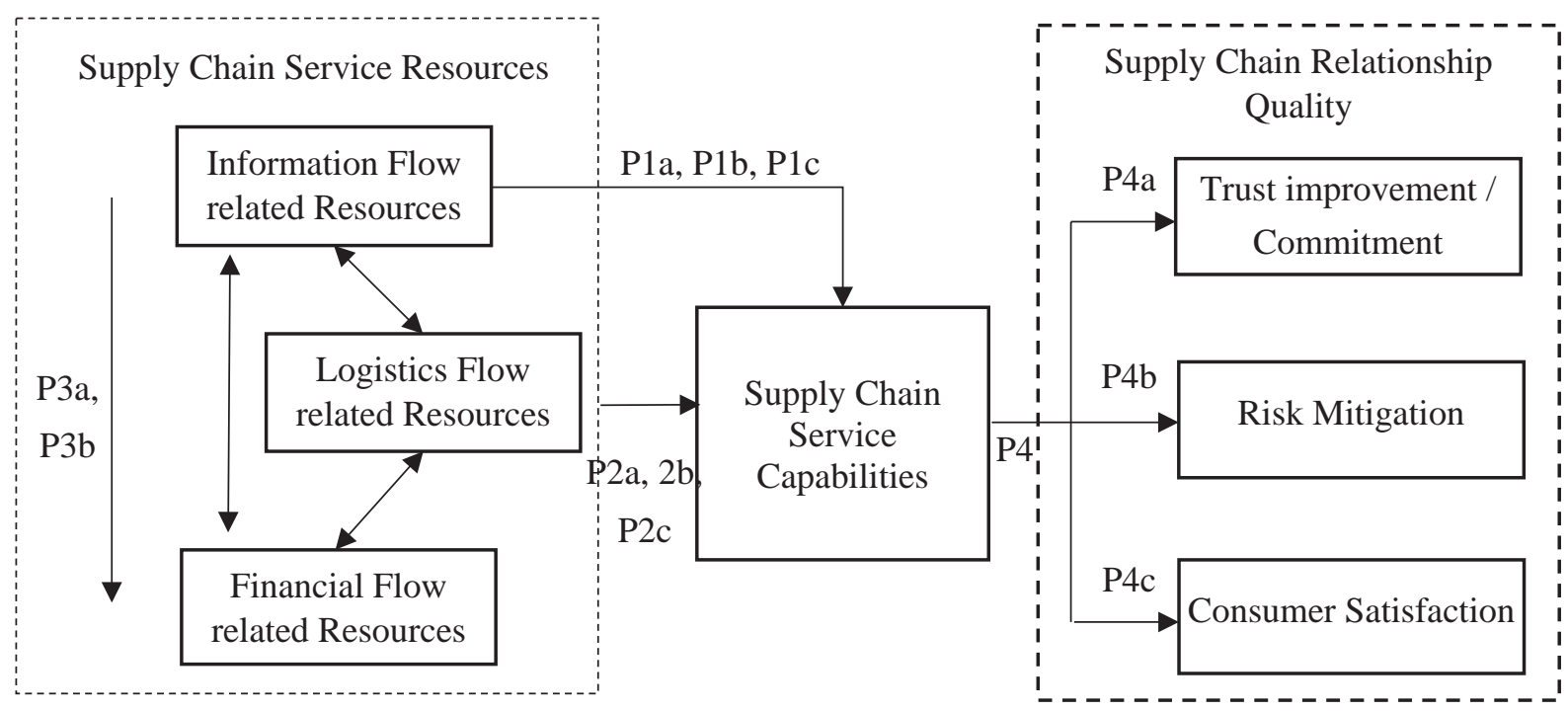

Figure 3 Proposed framework for three flows in cross-border e-commerce firms

Table 1 Basic information of the cases

\begin{tabular}{|c|c|c|c|c|c|}
\hline Company & Location & $\begin{array}{l}\text { Establish } \\
\text { Date }\end{array}$ & $\begin{array}{c}\text { Main } \\
\text { Business } \\
\text { Type }\end{array}$ & $\begin{array}{c}\text { No. of } \\
\text { Employee }\end{array}$ & Proactive Project \\
\hline OSell & Chongqing & 2010 & $\begin{array}{l}\text { B2B Export } \\
\text { business }\end{array}$ & $2000+$ & $\begin{array}{l}\text { OSell APP and Connect cross-border B2B } \\
\text { online/offline sharing platform }\end{array}$ \\
\hline Zongteng & Fuzhou & 2007 & $\begin{array}{l}\text { B2C Export } \\
\text { business }\end{array}$ & $1000+$ & $\begin{array}{l}\text { Global supply chain service platform with } \\
\text { B2C customer business as core }\end{array}$ \\
\hline BizArk & Nanjing & 2009 & $\begin{array}{l}\text { B2B Export } \\
\text { business }\end{array}$ & $300+$ & $\begin{array}{l}\text { Tailored overall solutions for overseas } \\
\text { marketing of Chinese enterprises }\end{array}$ \\
\hline Linca & Fuzhou & 2014 & $\begin{array}{l}\text { B2B Import } \\
\text { business }\end{array}$ & $200+$ & Full channel service e-commerce platform \\
\hline
\end{tabular}


Table 2 List of interviewees, their job titles and organisations

\begin{tabular}{|c|c|c|c|c|}
\hline Number & Company & Title & Interview Method & $\begin{array}{l}\text { Number of } \\
\text { Interviews }\end{array}$ \\
\hline 1 & Zongteng & Deputy General Manager & Face to Face & 2 \\
\hline 2 & Zongteng & Chief Operating Officer & $\begin{array}{l}\text { Face to Face } \\
\text { Telephone }\end{array}$ & 2 \\
\hline 3 & Zongteng & Chief HR Officer & Telephone & 1 \\
\hline 4 & Zongteng & HR Manger & Face to Face & 1 \\
\hline 5 & Zongteng & Administration Manger & Face to Face & 3 \\
\hline 6 & OSell & Co-Founder and Vice President & $\begin{array}{l}\text { Face to Face } \\
\text { Telephone }\end{array}$ & 1 \\
\hline 7 & OSell & Overseas Executive President & $\begin{array}{l}\text { Face to Face } \\
\text { Telephone }\end{array}$ & 2 \\
\hline 8 & OSell & Vice President & Face to Face & 2 \\
\hline 9 & OSell & Founder & Telephone & 3 \\
\hline 10 & OSell & $\begin{array}{c}\text { National Investment Vice } \\
\text { President }\end{array}$ & Telephone & 3 \\
\hline 11 & Linca & $\begin{array}{l}\text { Executive President of Linca e- } \\
\text { Commerce Business School }\end{array}$ & Telephone & 2 \\
\hline 12 & Linca & $\begin{array}{c}\text { Director of Overseas Business } \\
\text { Unit }\end{array}$ & Face to Face & 2 \\
\hline 13 & Linca & Logistics Division Director & Telephone & 3 \\
\hline 14 & Linca & Technical Director & Face to Face & 2 \\
\hline 15 & Linca & Director of Cross-Border Business & $\begin{array}{l}\text { Face to Face } \\
\text { Telephone }\end{array}$ & 3 \\
\hline 16 & BizArk & Founder \& CEO & Telephone & 1 \\
\hline 17 & BizArk & Business Development Manager & Face to Face & 1 \\
\hline 18 & BizArk & National Executive Director & Face to Face & 2 \\
\hline 19 & BizArk & General Manager of South China & $\begin{array}{l}\text { Face to Face } \\
\text { Telephone }\end{array}$ & 2 \\
\hline 20 & BizArk & Director of Marketing Promotion & Face to Face & 2 \\
\hline 21 & BizArk & Project Manager & Face to Face & 1 \\
\hline Total & & & & 41 \\
\hline
\end{tabular}



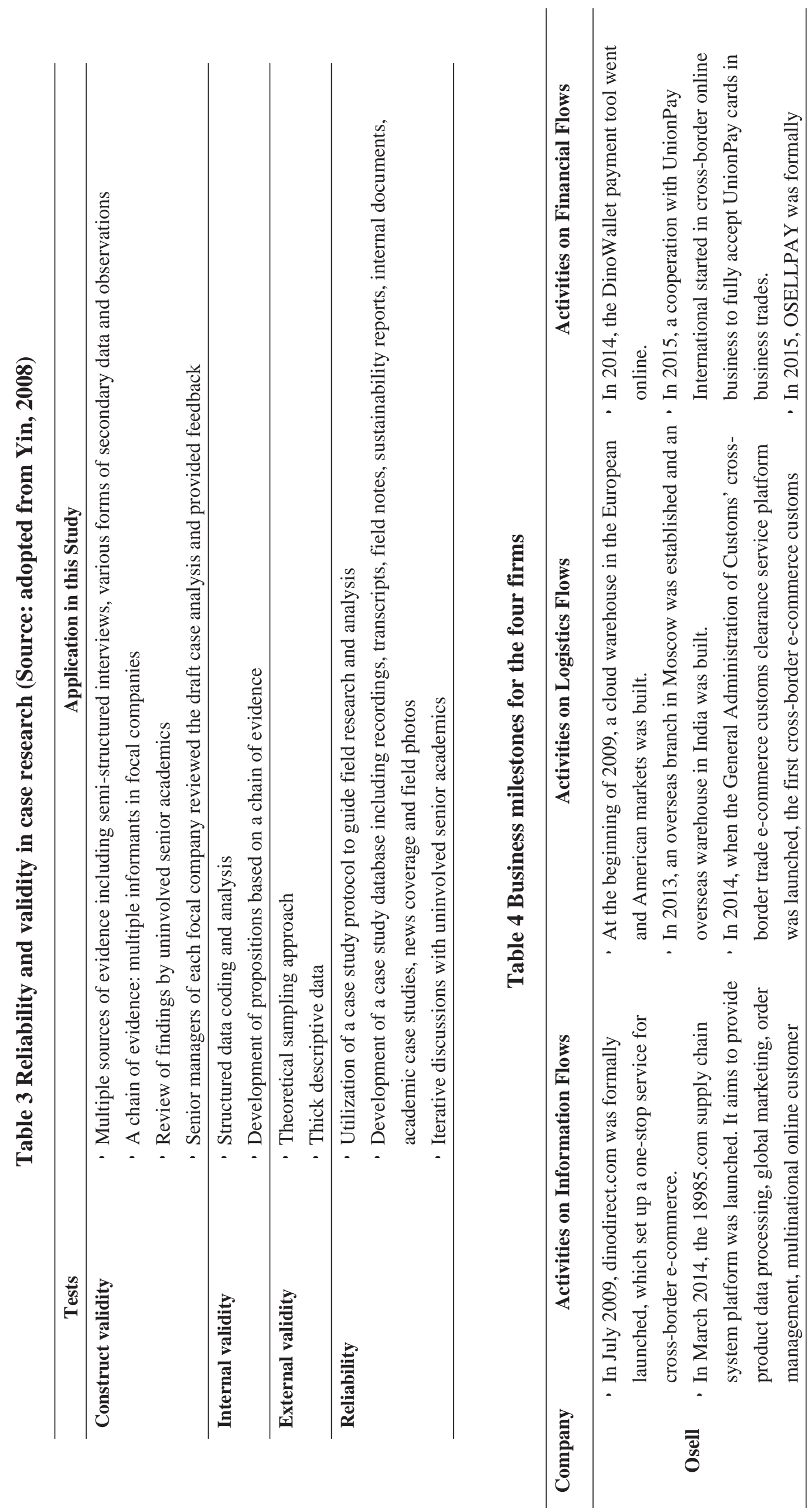


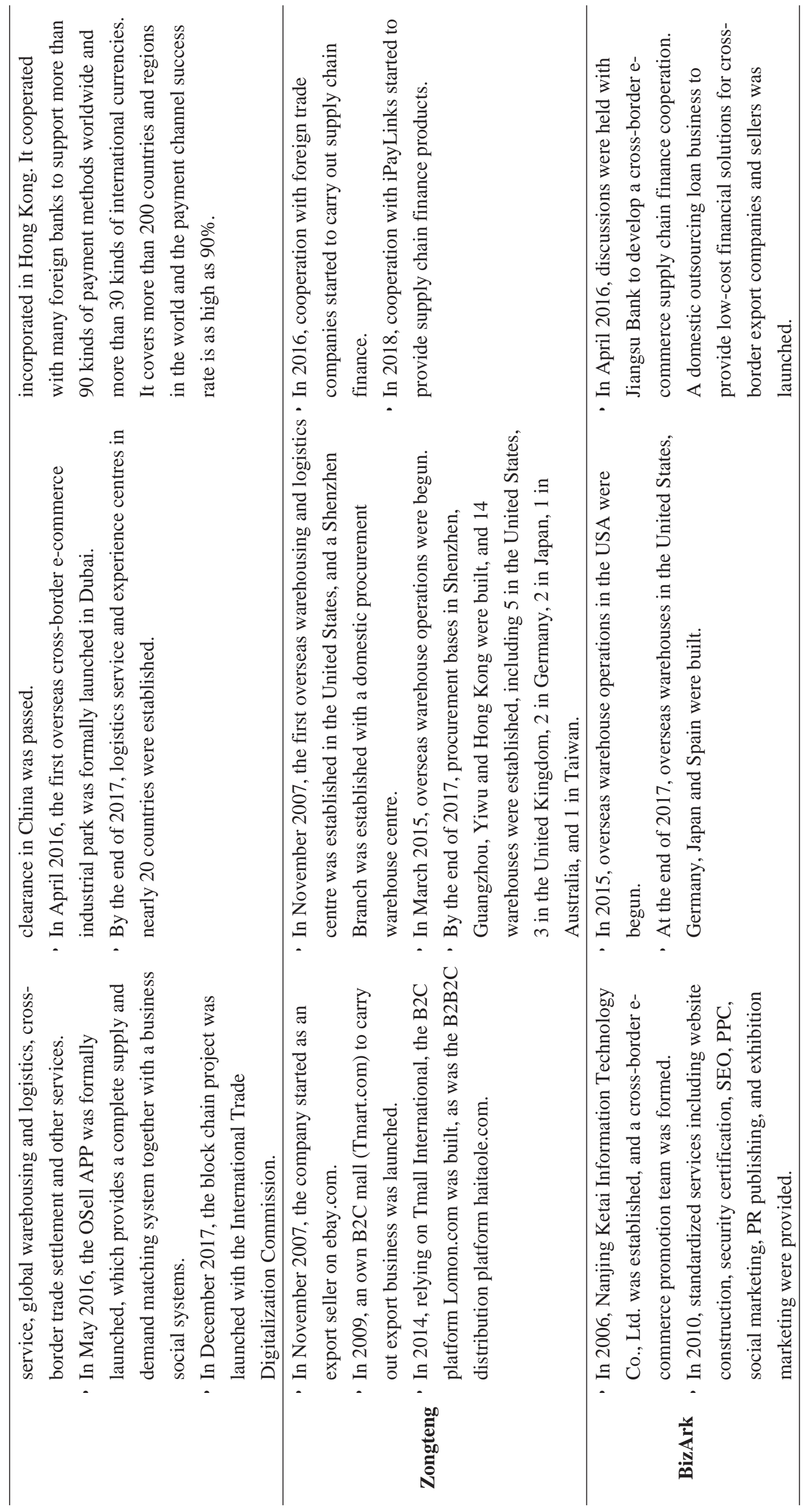




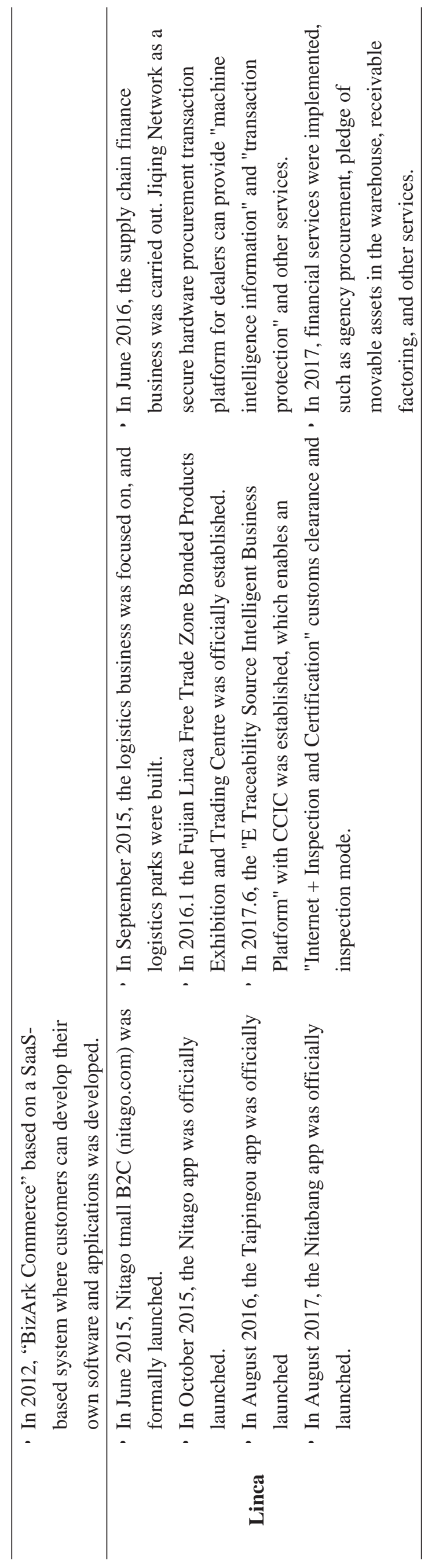




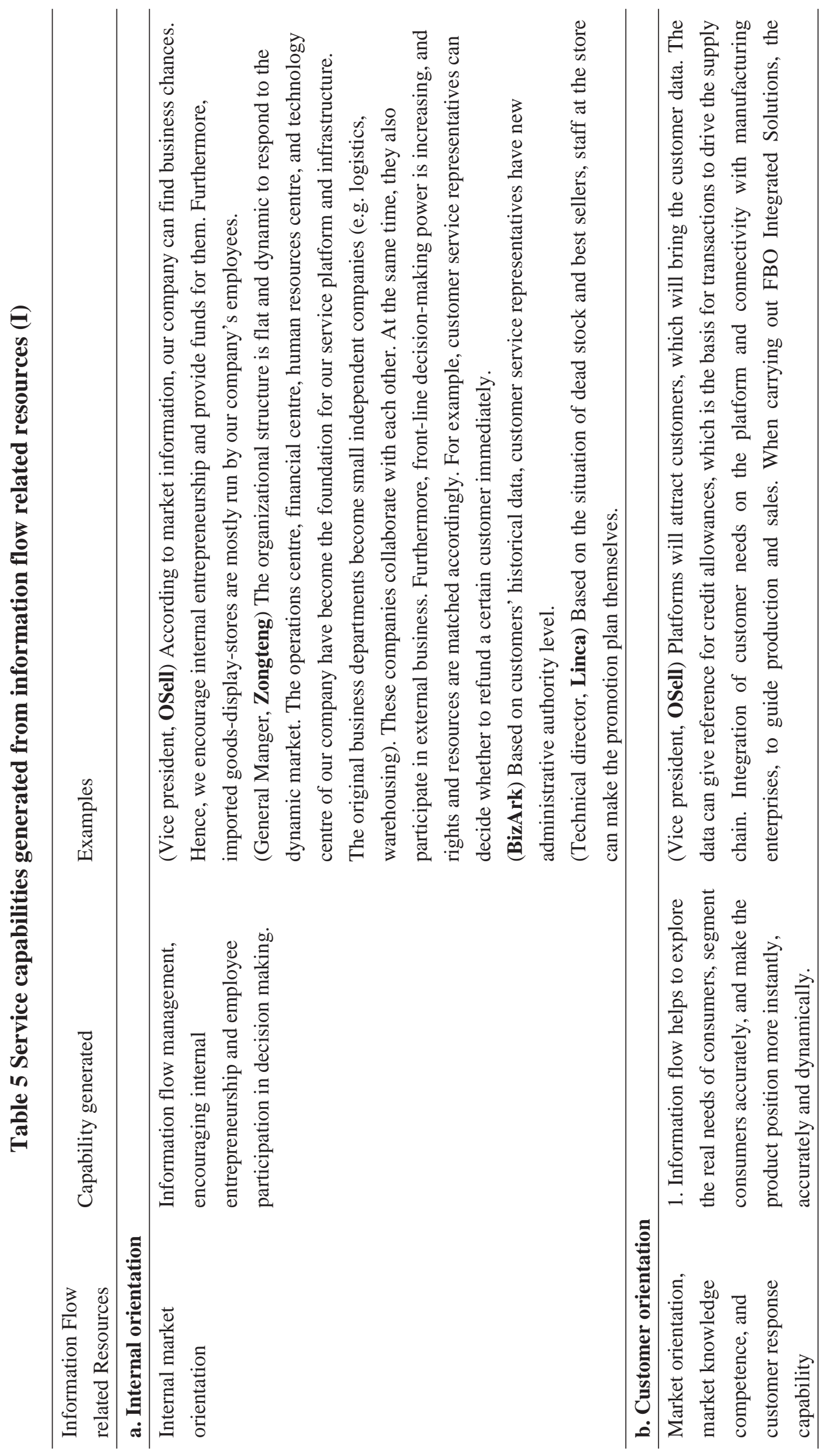




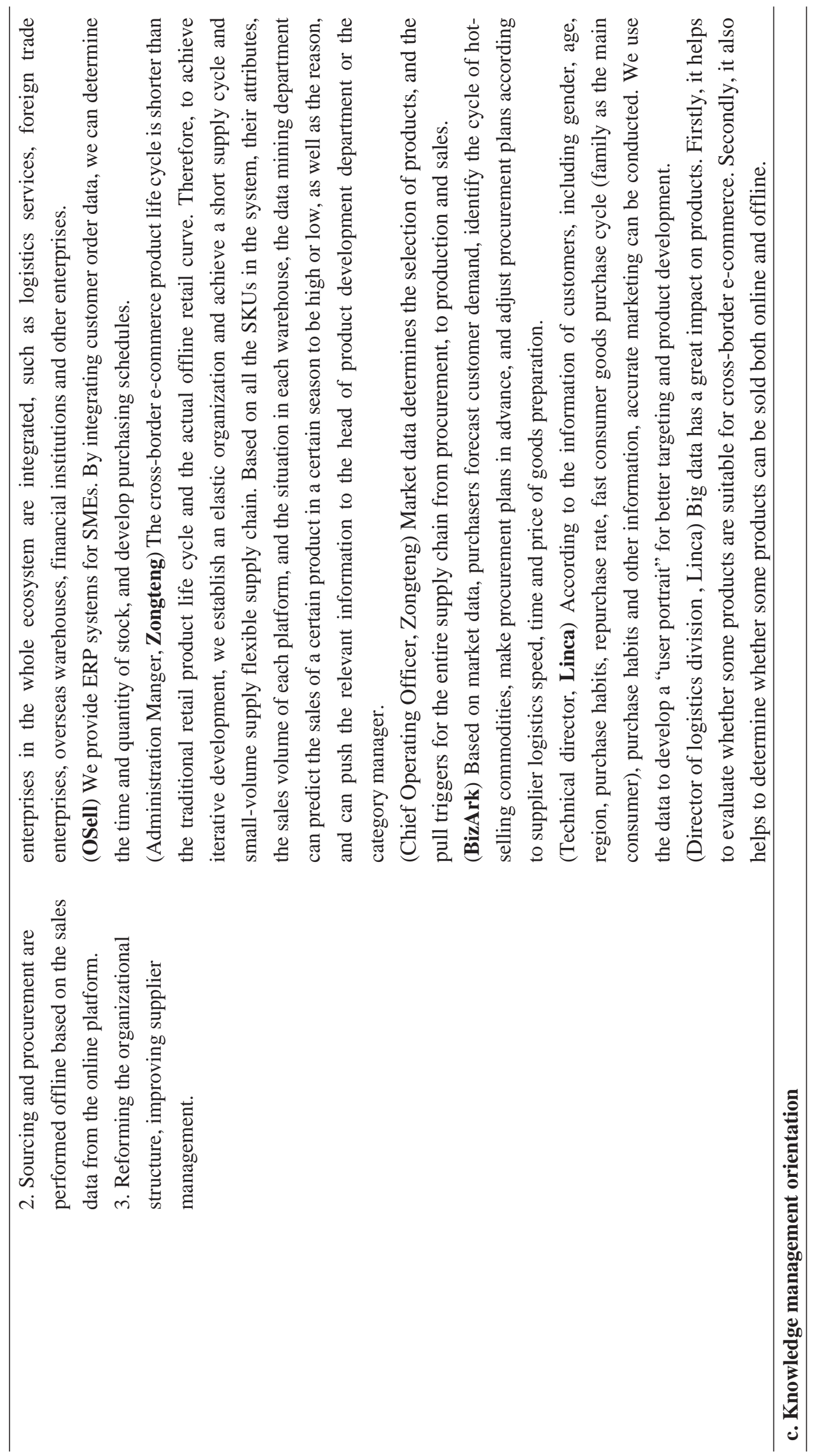




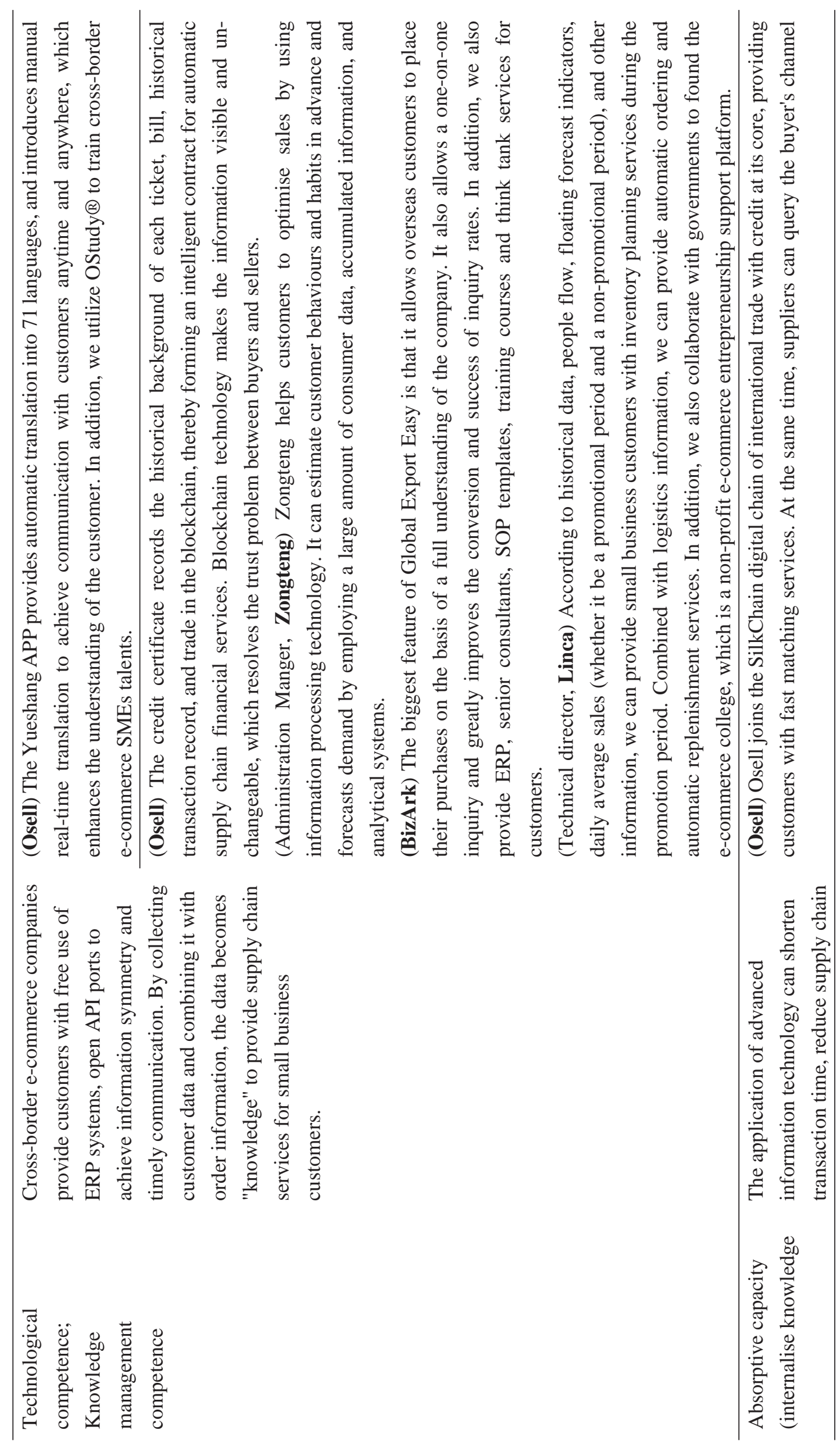




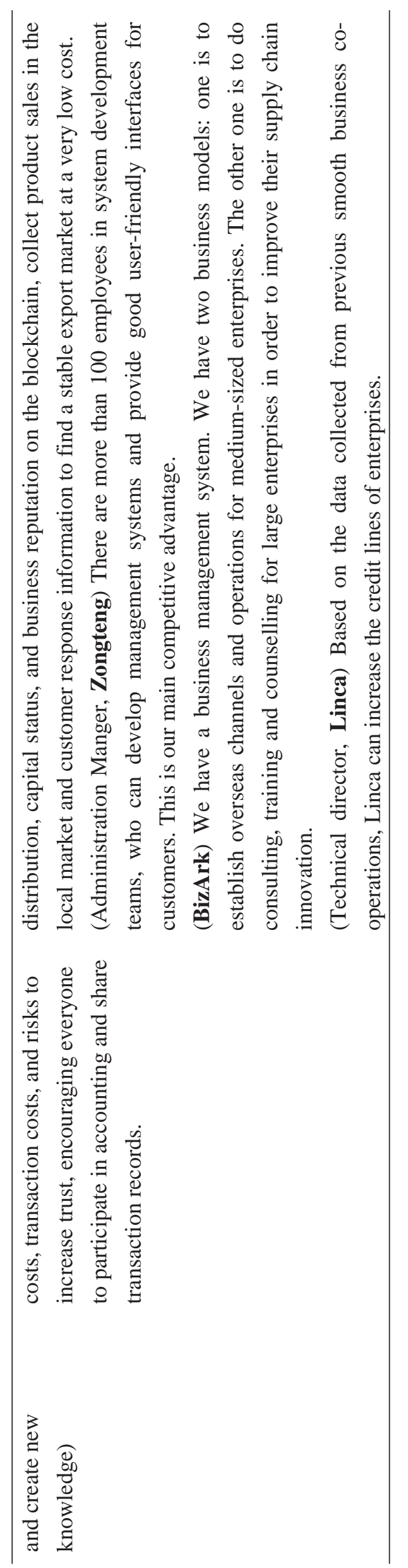




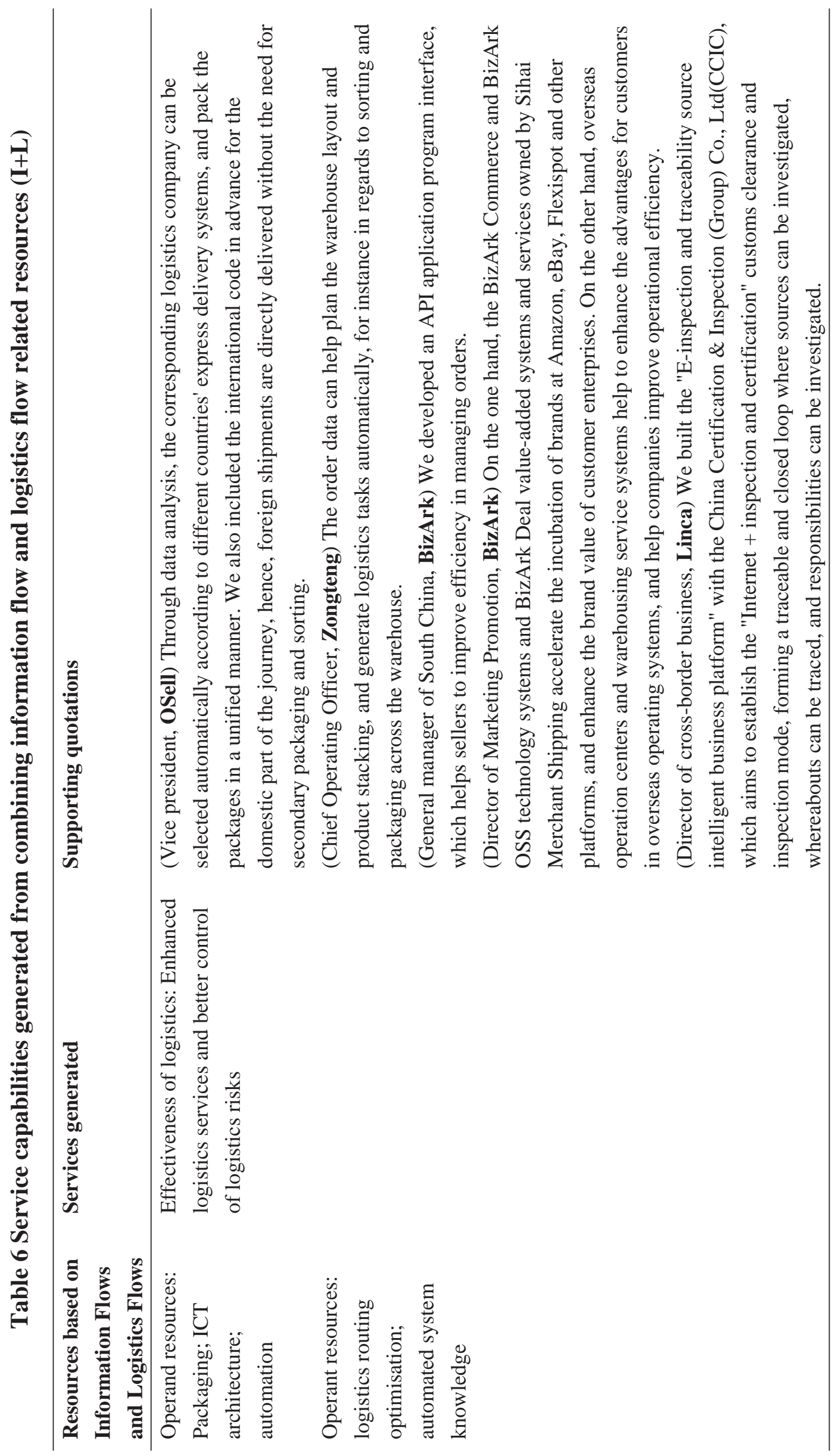




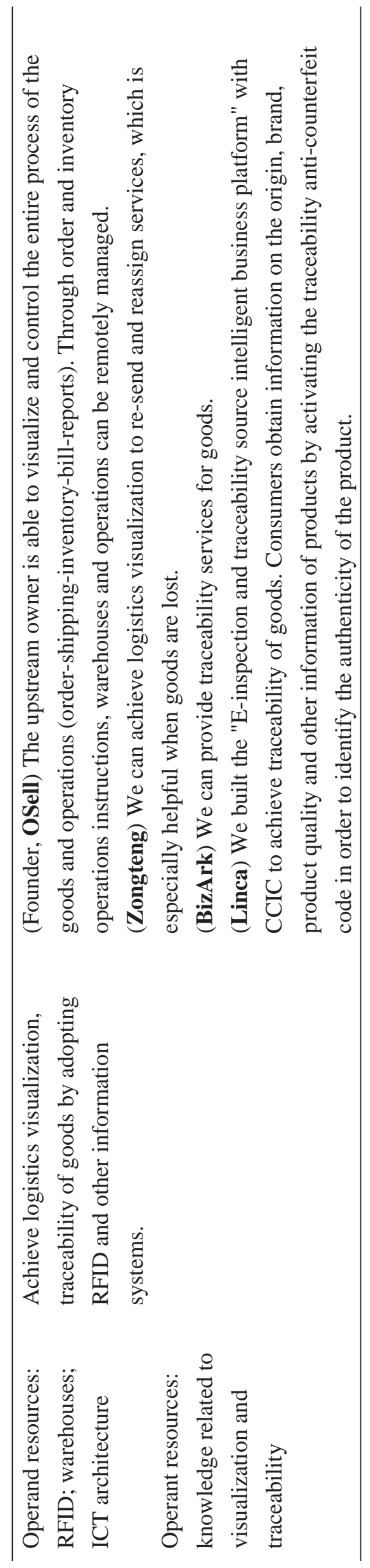




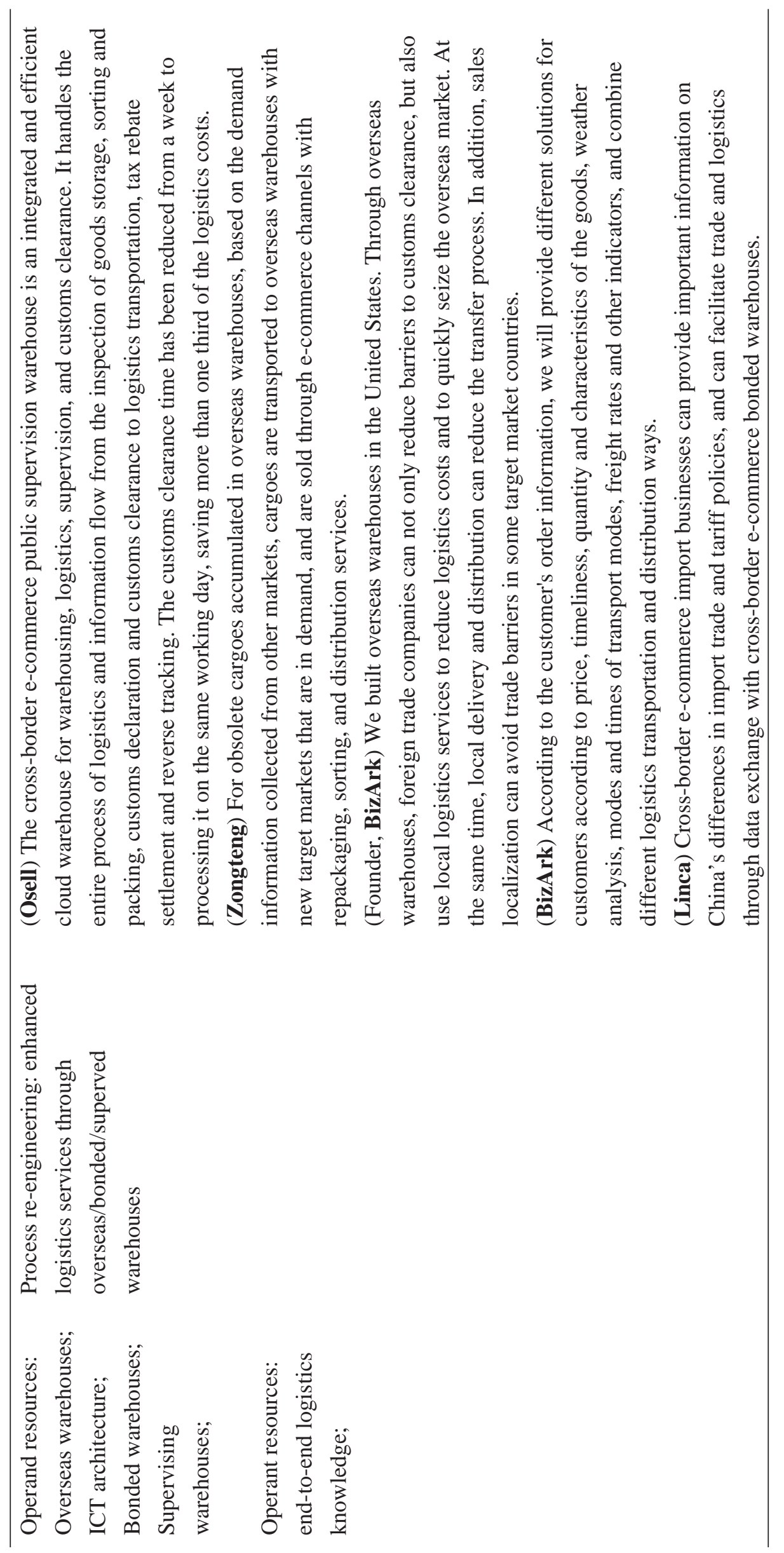




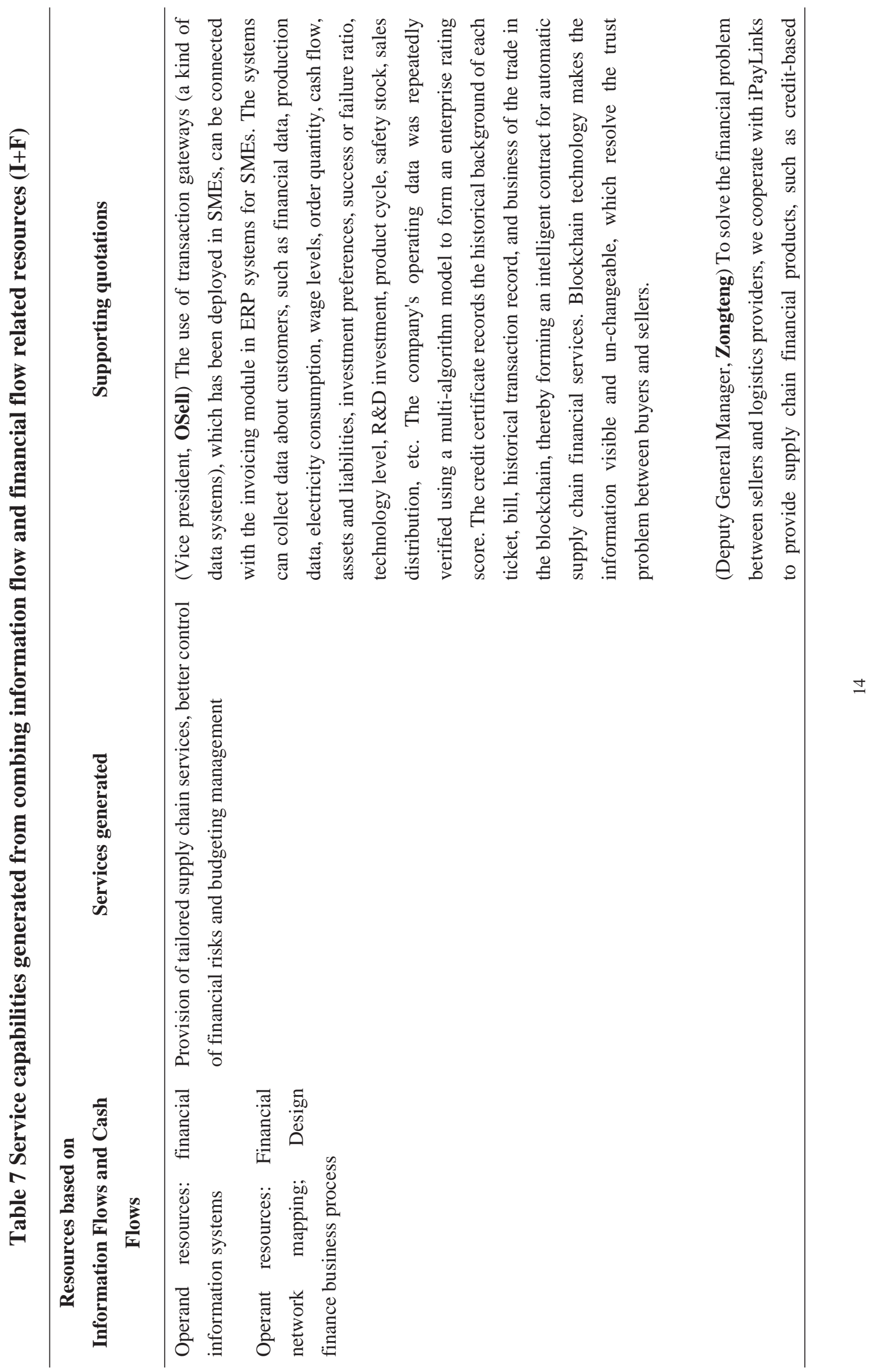




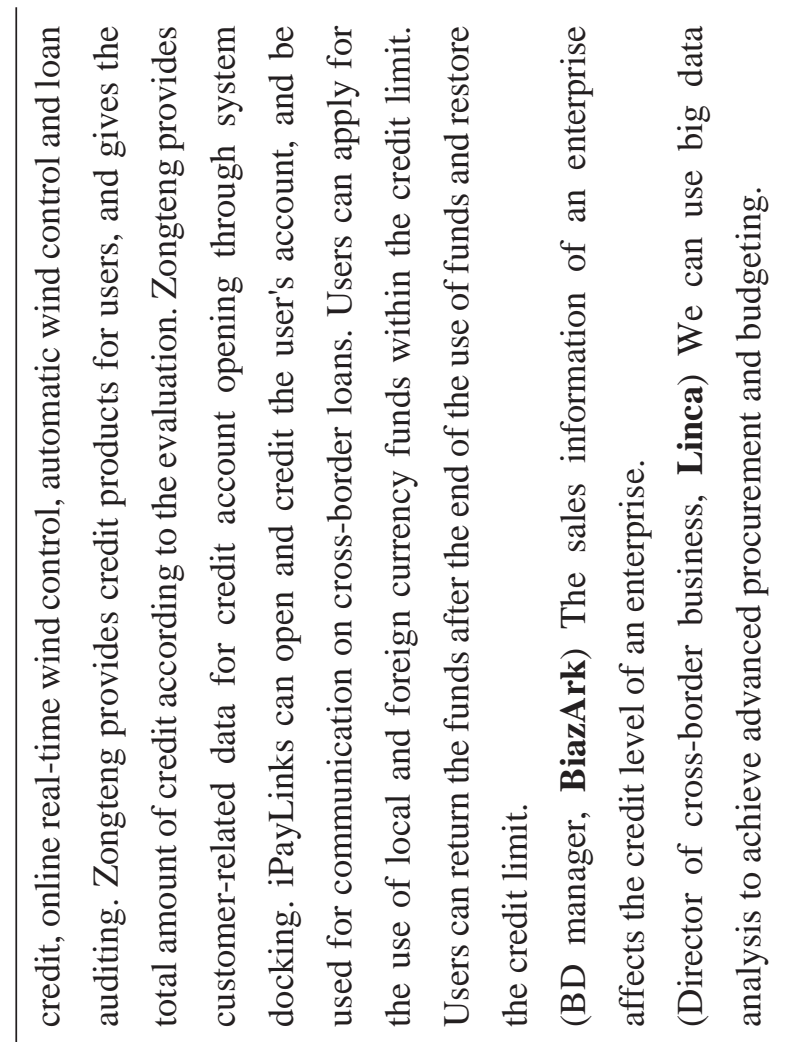




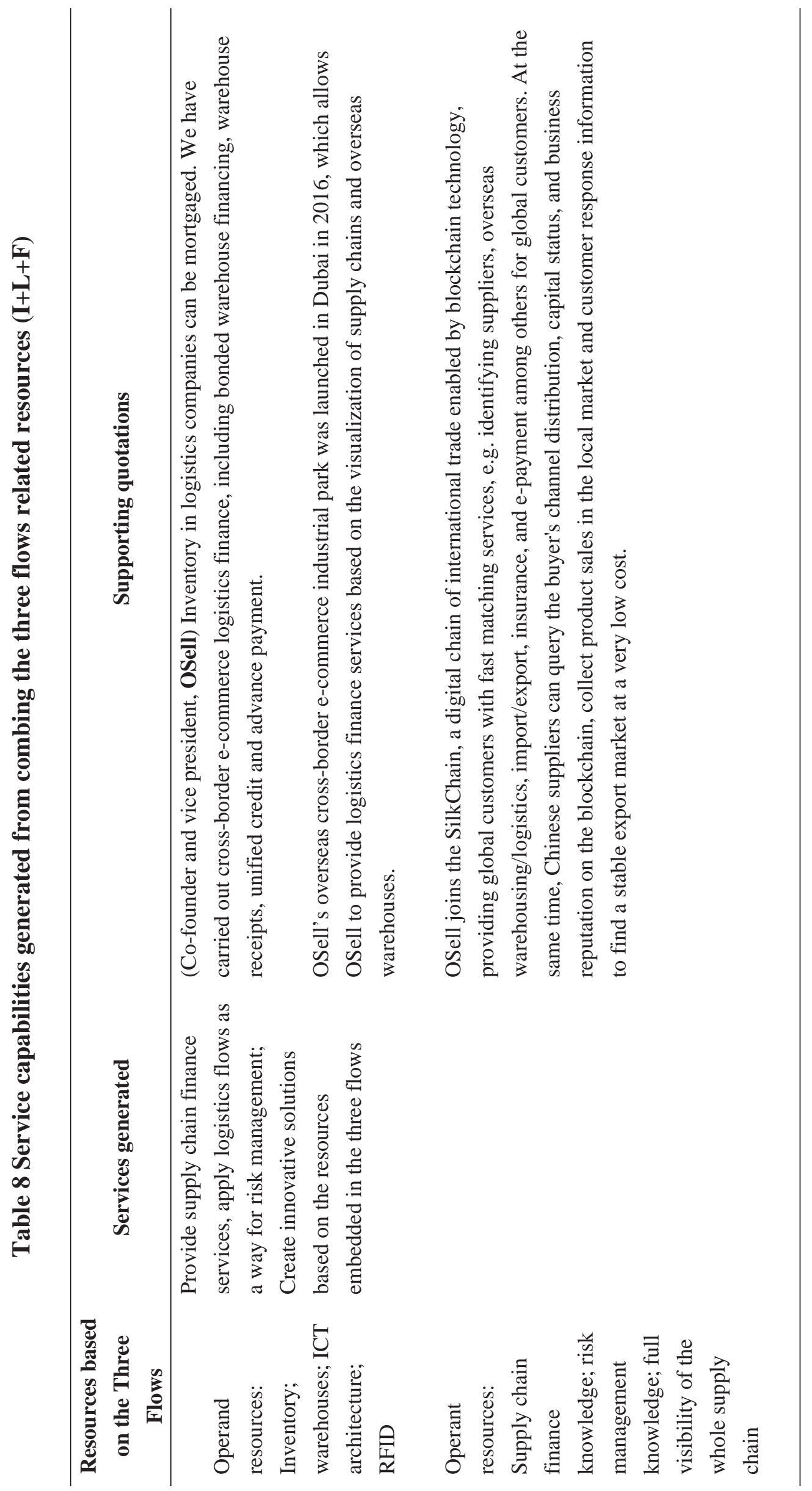




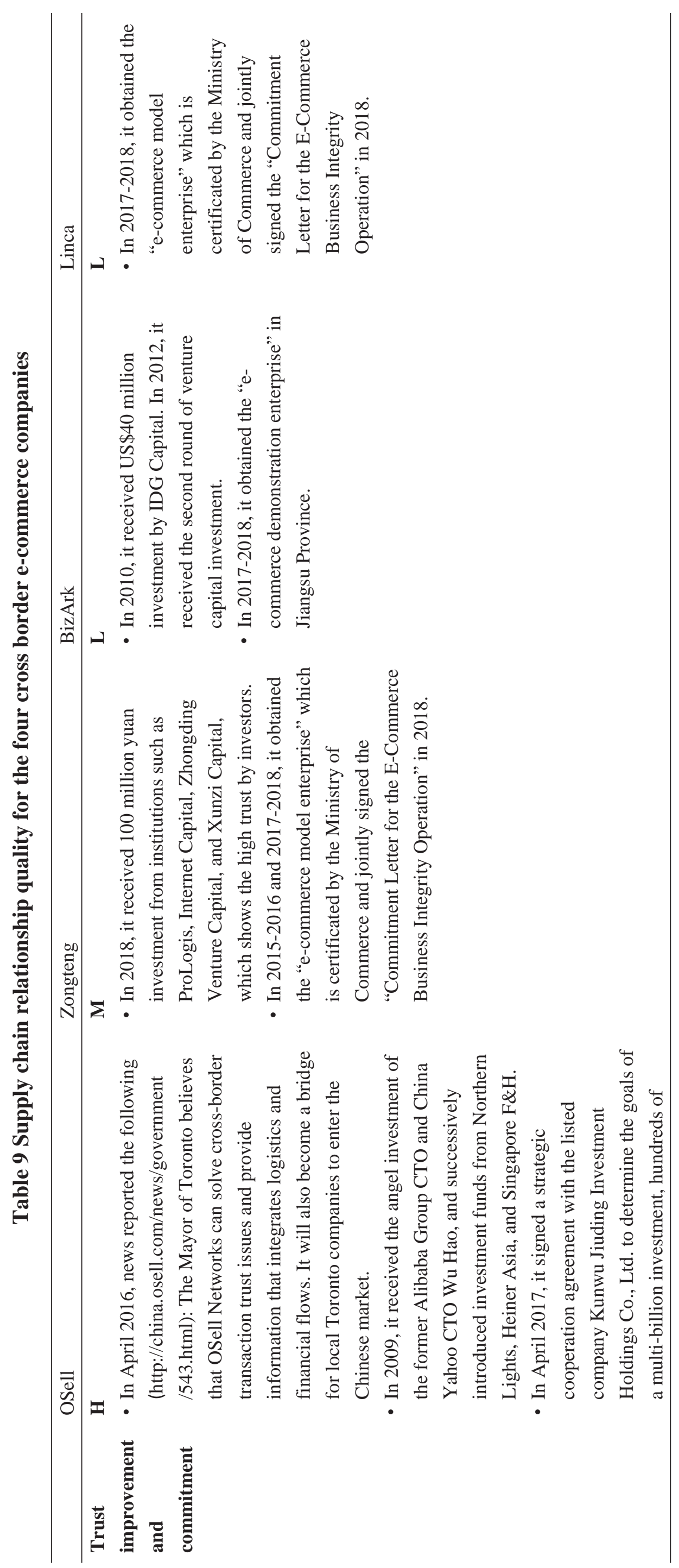




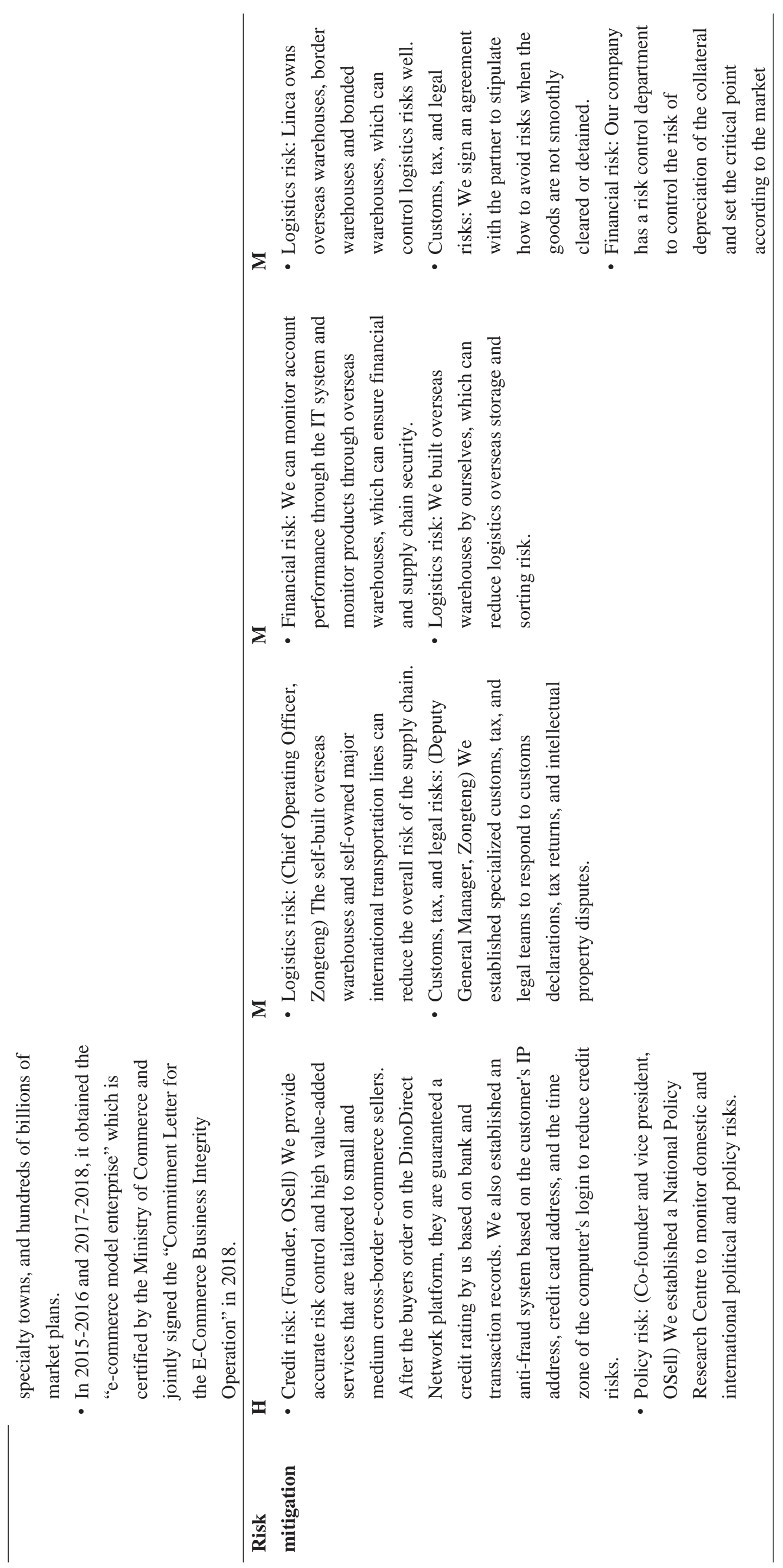




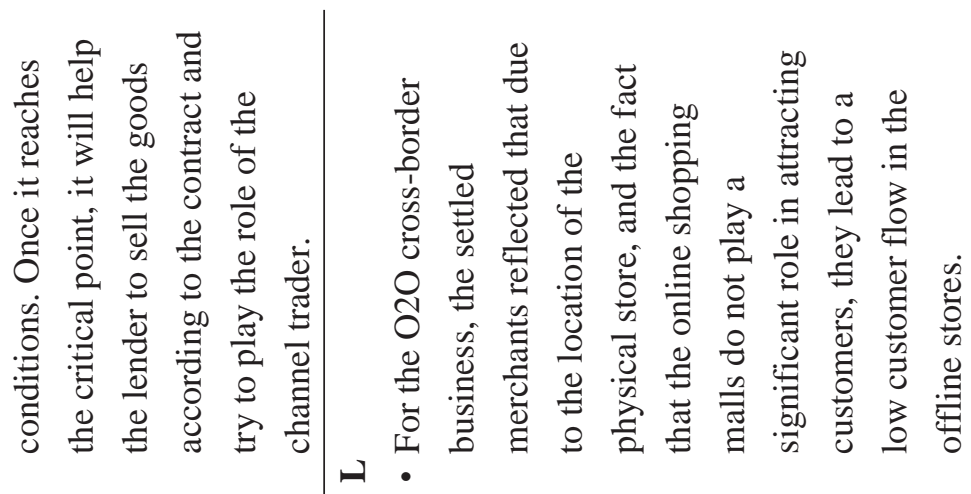

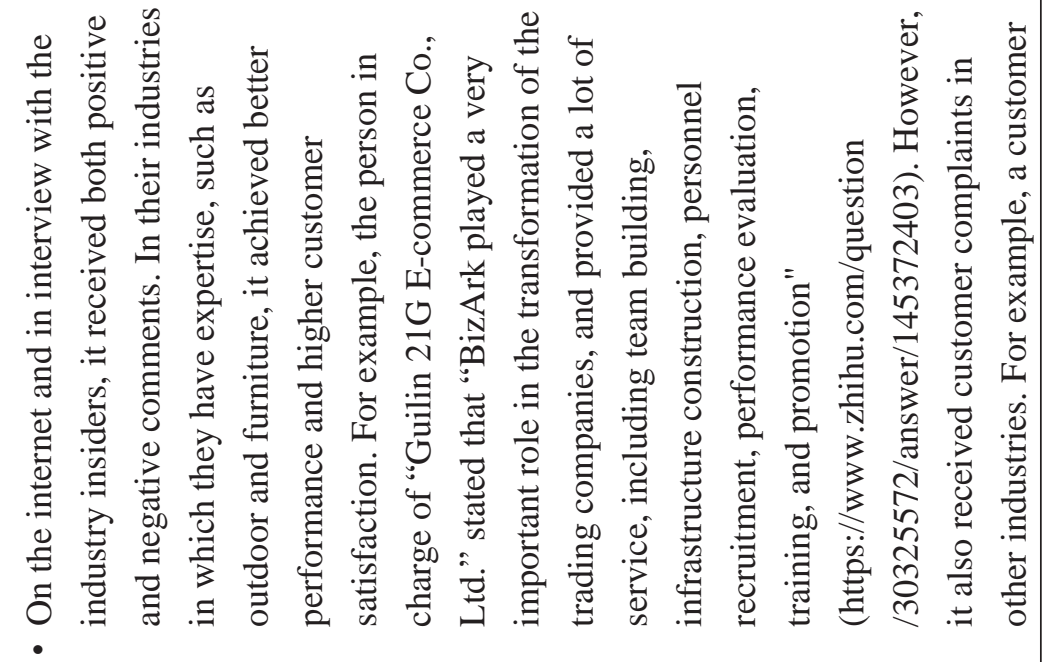

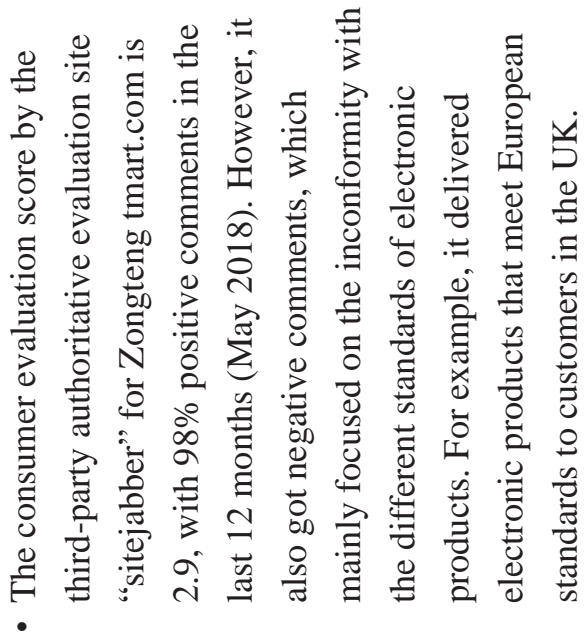

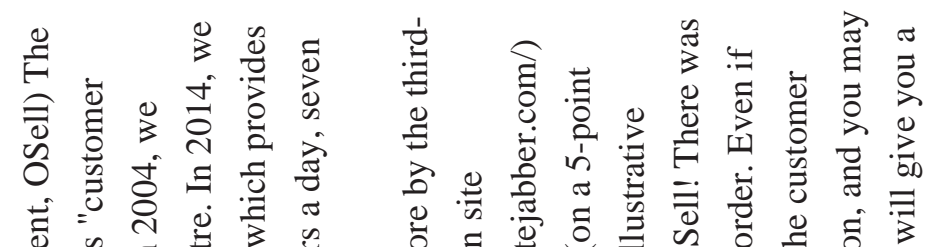

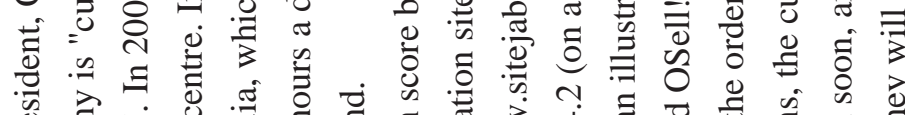

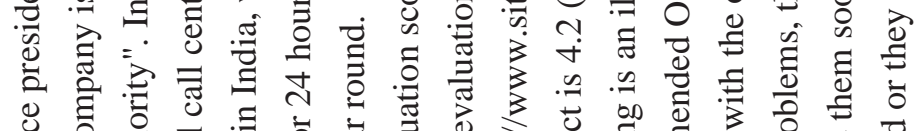

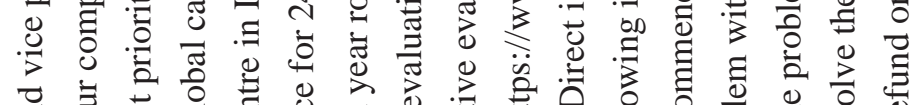

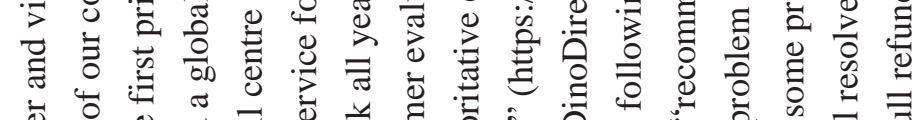

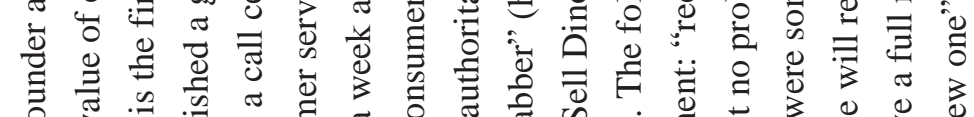

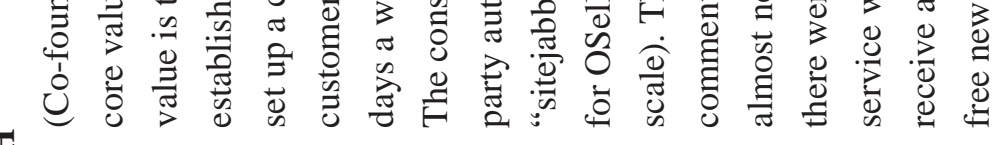




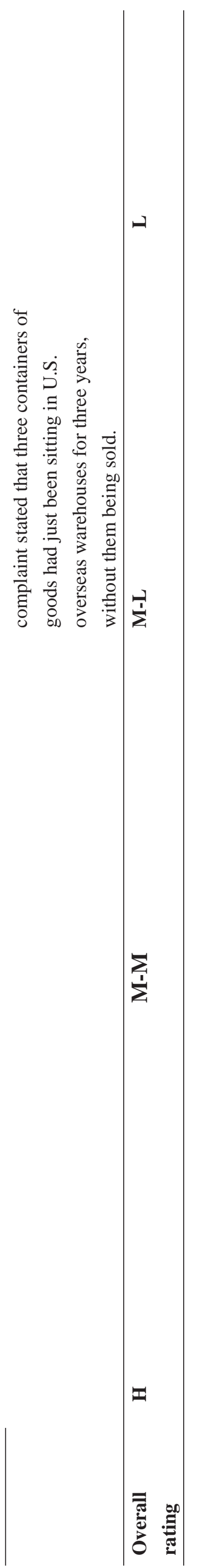

